\title{
Glucagon-induced extracellular CAMP regulates hepatic lipid metabolism
}

\author{
Sihan Lv'1, Xinchen Qiu1,2, Jian Lì1,2, Jinye Liang², Weida Li², Chao Zhang², \\ Zhen-Ning Zhang' ${ }^{2}$ and Bing Luan'
}

'Department of Endocrinology, Shanghai Tenth People's Hospital, School of Medicine, Tongji University, Shanghai, China

2Translational Medical Center for Stem Cell Therapy \& Institute for Regenerative Medicine, Shanghai East Hospital, School of Life Sciences and Technology, Tongji University, Shanghai, China
Correspondence should be addressed to Z-N Zhang or B Luan Email znzhang@tongji.edu.cn or bluan@tongji.edu.cn

\begin{abstract}
Hormonal signals help to maintain glucose and lipid homeostasis in the liver during the periods of fasting. Glucagon, a pancreas-derived hormone induced by fasting, promotes gluconeogenesis through induction of intracellular cAMP production. Glucagon also stimulates hepatic fatty acid oxidation but the underlying mechanism is poorly characterized. Here we report that following the acute induction of gluconeogenic genes Glucose 6 phosphatase (G6Pase) and Phosphoenolpyruvate carboxykinase (Pepck) expression through CAMP-response element-binding protein (CREB), glucagon triggers a second delayed phase of fatty acid oxidation genes Acyl-coenzyme A oxidase (Aox) and Carnitine palmitoyltransferase 1a (Cpt1a) expression via extracellular cAMP. Increase in extracellular CAMP promotes PPAR $\alpha$ activity through direct phosphorylation by AMP-activated protein kinase (AMPK), while inhibition of cAMP efflux greatly attenuates Aox and Cpt1a expression. Importantly, CAMP injection improves lipid homeostasis in fasted mice and obese mice, while inhibition of cAMP efflux deteriorates hepatic steatosis in fasted mice. Collectively, our results demonstrate the vital role of glucagon-stimulated extracellular CAMP in the regulation of hepatic lipid metabolism through AMPK-mediated PPAR $\alpha$ activation. Therefore, strategies to improve cAMP efflux could serve as potential new tools to prevent obesity-associated hepatic steatosis.
\end{abstract}

\author{
Key Words \\ - glucagon \\ - extracellular CAMP \\ - AMPK \\ - PPARo \\ - fatty acid oxidation
}

\section{Introduction}

The expanding global epidemic of obesity has become a major threat to human health worldwide (Ford et al. 2004). Obesity is associated with an ectopic accumulation of fat in non-adipose tissues such as in the liver (Sun \& Karin 2012). Disrupted lipid metabolism including fatty acid oxidation and de novo lipogenesis in liver results in the development of hepatic steatosis and contributes to the development of hepatic insulin resistance (Marchesini et al. 2003, Hooper et al. 2011). Thus, better understanding of the underlying mechanism and regulation for fatty acid oxidation would greatly help elucidating novel strategies to treat obesity-induced hepatic steatosis.

The liver is a major organ that controls glucose and lipid metabolism in response to hormonal signals. Dedicated transcription regulatory network is involved in the hepatic response to fasting. During the fasted state, one of the major circulating hormones required for liver function is glucagon. Increased glucagon stimulates the gluconeogenesis via induction of intracellular cAMP. Induction of cAMP-dependent protein kinase A (PKA) by cAMP subsequently leads to activation of the CREB

Published by Bioscientifica Ltd. 
regulated transcription coactivators (CRTCs)/CREB (Altarejos \& Montminy 2011) and the Class II histone deacetylases (HDACs)/FOXO pathways (Mihaylova et al. 2011, Wang et al. 2011) and promotes expression of gluconeogenic genes such as Pepck and G6Pase. Glucagon also regulates fatty acid oxidation in the liver (Longuet et al. 2008, von Meyenn et al. 2013). Glucagon stimulation is sufficient to reduce plasma triacylglycerol and non-esterified fatty acid (NEFA) levels and glucagon receptor knockout mice show increased triacylglycerol and NEFA levels during the fasted state (Longuet et al. 2008). PPAR $\alpha$, a master transcription factor that regulates expression of fatty acid oxidation genes such as Aox, Cpt1a and Medium-chain acyl-CoA dehydrogenase (Mcad), serves as the major target of glucagon's action. Glucagon stimulates PPAR $\alpha$ activity and targets fatty acid oxidation gene expression, which is diminished in PPAR $\alpha$ knockout mice (Longuet et al. 2008). Although AMPK is implicated to mediate glucagon-induced PPAR $\alpha$ activity, the underlying mechanism for AMPK activation by glucagon stimulation and AMPK regulation of $\operatorname{PPAR} \alpha$ activity remains poorly understood. Glucagon-stimulated gluconeogenesis and fatty acid oxidation are intertwined. The expression of Pepck (Tachibana et al. 2005, Bernal-Mizrachi et al. 2007) and G6Pase (Im et al. 2011) is also regulated by PPAR $\alpha$ and PPAR $\alpha$ knockout mice are consistently hypoglycemic due to impaired hepatic glucose output. Additionally, Cpt1a has been reported to be a CREB target gene (Louet et al. 2002).

cAMP has been reported to have both intracellular and extracellular functions. cAMP is secreted from multiple tissues including kidney (Coulson \& Bowman 1974), liver (Constantin et al. 1997) and adipose tissue (Strouch et al. 2005) and cell types such as hepatocytes (Pilkis et al. 1975), glomerular epithelial cells (Ardaillou et al. 1993), renal proximal tubule cells (Boumendil-Podevin \& Podevin 1977) and adipocytes (Butcher et al. 1968). Extracellular cAMP functions as a paracrine or endocrine molecule to regulate the functions of tissues. Glucagon not only stimulates intracellular cAMP accumulation in the liver, but also induces a significant release of liver-borne cAMP into the blood (Exton et al. 1971b, Godinho et al. 2015). Extracellular cAMP mediates glucagon actions such as endocrine inhibition of sodium and phosphate reabsorption in the renal proximal tubule (Ahloulay et al. 1996). Liverborne extracellular cAMP is also able to mimic glucagon effect on glucose metabolism in the liver (Northrop \& Parks 1964). However, understanding the physiological function of cAMP in vivo and its pathological contribution to metabolic dysfunction in type 2 diabetes (T2DM) still requires further investigation.

Here we report a novel role of glucagon-stimulated extracellular cAMP on fatty acid oxidation and lipid metabolism in the liver. Extracellular cAMP activates hepatic AMPK, which in turn phosphorylates PPAR $\alpha$ and increases its transcriptional activity and fatty acid oxidation gene expression. When administrated in vivo, cAMP greatly ameliorates obesity-induced hepatic steatosis. Our data thus provide new evidence demonstrating the effect of extracellular cAMP on hepatic lipid homeostasis under physiological and pathological conditions. Further, we demonstrate a potential novel therapeutic strategy for the treatment of obesity-associated hepatic steatosis.

\section{Materials/subjects and methods}

\section{Cells, antibodies and reagents}

Primary hepatocytes were prepared as described (Dentin et al. 2004). Briefly, livers from fed mice were perfused with Hank's balanced salt solution (Invitrogen) followed by collagenase (Type IV) (Sigma) at a rate of $6 \mathrm{~mL} / \mathrm{min}$ through the portal vein. Cells were seeded in medium M199 (Invitrogen), supplemented with $0.2 \%$ $(\mathrm{w} / \mathrm{v})$ bovine serum albumin, and $2 \%(\mathrm{v} / \mathrm{v})$ fetal bovine serum (FBS). The medium was replaced with fresh M199 medium after $2 \mathrm{~h}$. Cells were then infected with 1 plaque-forming unit per cell (pfu/cell) of Ad-PPAR $\alpha$, Ad-PPAR $\alpha$ S452A, Ad-AMPK CA or Ad-GFP for $24 \mathrm{~h}$ for overexpression and Ad-PPAR $\alpha$, Ad-MRP4i or Ad-USi for $48 \mathrm{~h}$ for RNAi-mediated knockdown. HEK293T cells were maintained in DMEM with 10\% FBS and transfected with Lipofectamine 2000 (Invitrogen). HepG2 cells (human hepatoma cells) were maintained in Ham's F12 with 10\% FBS and transfected with FuGENE6 (Roche). Cell treatment information for each experiment was indicated in the figure legend. Anti-pAMPK, AMPK and phosphor(Ser/Thr) antibodies were purchased from Cell Signaling Technology. Anti- $\alpha$-tubulin, PPAR $\alpha$ and MRP4 antibodies were purchased from Abcam. cAMP was purchased from Promega. AICAR was purchased from Tocris (Ellisville, MO, USA). Glucagon, Compound C, Probenecid, IMBX, AMPCP, NBTI, DPSPX and GW6471 were purchased from Sigma. Oltipraz was purchased from MedChem Express (Princeton, NJ, USA). Plasmids expressing WT PPAR $\alpha$, PPAR $\alpha$ S452A and AMPK CA (AMPK T172D) http://joe.endocrinology-journals.org DOI: $10.1530 / J O E-16-0649$ (c) 2017 Society for Endocrinology Printed in Great Britain
Published by Bioscientifica Ltd 
were provided by Dr Marc Montminy (Salk Institute, La Jolla, USA). RNAi was constructed using the sequence 5'-AGTTGGAGCAGGCAAG-3' for MRP4i and sequence 5'-GGGATCAAAGAGGAGCCAGTGC-3' for PPARoi.

\section{Animals and adenovirus}

C57BL/6J mice and $o b / o b$ mice were purchased from Shanghai Laboratory Animal Center (Shanghai, China) and were adapted to colony cages with $12 \mathrm{~h}$ light/darkness cycle in a temperature-controlled environment with free access to water and standard irradiated rodent diet (5\% fat; Research Diet, D12450, New Brunswick, NJ, USA). For high-fat diet (HFD) studies, 6-week-old mice were maintained on HFD (60\% fat; Research Diets, D12492) for 12 weeks. For adenovirus injection, $10^{9} \mathrm{pfu}$ Ad-G6Paseluc or Ad-Aox-luc and $5 \times 10^{7} \mathrm{pfu}$ Ad-RSV- $\beta$-galactosidase ( $\beta$-gal) for in vivo imaging, $1 \times 10^{8} \mathrm{pfu}$ Ad-unspecific RNAi (USi), Ad-MRP4 RNAi (MRP4i) for in vivo RNAi-mediated knockdown were delivered by tail vein injection. For cAMP injection, mice were intravenously injected with $20 \mathrm{mg} / \mathrm{kg}$ cAMP dissolved in $0.9 \%$ saline or $0.9 \%$ saline daily for 6 days. After day 6 injection, mice were fasted for $12 \mathrm{~h}$, injected with cAMP and remained fasted for another $12 \mathrm{~h}$ before being killed. For AMPCP injection, mice were intravenously injected with $20 \mathrm{mg} / \mathrm{kg}$ AMPCP daily for 3 days as previously described (Ponce et al. 2016). For oltipraz injection, mice were intraperitoneally injected with $150 \mathrm{mg} / \mathrm{kg}$ oltipraz or coin oil. All animal studies were approved by the Animal Experiment Committee of Tongji University and in accordance with the guidelines of school of medicine, Tongji University. All adenovirus were constructed using AdEasy Adenoviral Vector System according to the manufacturer's instruction (Agilent Technologies).

\section{In vivo imaging}

Mice were imaged on Day 3-5 after adenovirus delivery. Mice were fasted for $12 \mathrm{~h}$ or $48 \mathrm{~h}$, respectively, and injected intraperitoneally with $50 \mathrm{mg} / \mathrm{kg}$ nembutal (Abbott Laboratories) and $100 \mathrm{mg} / \mathrm{kg}$ sterile firefly D-luciferin (Qianchen, Shanghai, China) before imaging. Mice were imaged using the IVIS 100 Imaging System (PerkinElmer) and data were analyzed using Living Image software (Xenogen) as described (Liu et al. 2008). Liver samples were taken immediately after imaging and lysates were subjected to $\beta$-gal assay to ensure the equal level of adenoviral infection.

\section{In vitro analysis}

Mouse tissues were frozen in liquid nitrogen and kept at $-80^{\circ} \mathrm{C}$ until further use. Livers were homogenized using tissue homogenizer and further sonicated at $4^{\circ} \mathrm{C}$ in lysis buffer $(150 \mathrm{mM} \mathrm{NaCl}, 50 \mathrm{mM}$ Tris- $\mathrm{HCl}, \mathrm{pH} 7.5$, $5 \mathrm{mM}$ EDTA, $30 \mathrm{mM}$ sodium pyrophosphate, $30 \mathrm{mM}$ sodium fluoride, $1 \%$ Triton-X 100 , and protease inhibitor cocktail). Lysates were centrifuged for $10 \mathrm{~min}$ at $20,000 \boldsymbol{g}$ at $4^{\circ} \mathrm{C}$ and supernatants were reserved for $\beta$-gal activity and protein determination. Serum triacylglycerol, NEFA and total ketones were determined using commercially available kits (WAKO). Liver samples were weighted and incubated overnight at $55^{\circ} \mathrm{C}$ in ethanolic $\mathrm{KOH}$ with vortex. The supernatants were supplied with $50 \%$ $\mathrm{EtOH}$ and $\mathrm{MgCl}_{2}$ (Norris et al. 2003). After incubation on ice, samples were centrifuged and supernatants were subjected to glycerol determination with WAKO LabAssay Triglycerides kit. Lipids were extracted from liver samples using Lipid Extraction Kit (Sigma) and used for NEFA detection with WAKO LabAssay NEFA kit. Intracellular and extracellular cAMP concentrations were measured using a cAMP ELISA kit according to the manufacturer's instruction (Cayman Chemical Company). Briefly, cell culture media or serum were diluted in ELISA buffer and assayed directly to measure extracellular cAMP levels. To detect intracellular cAMP levels, cultured cells were incubated with $0.1 \mathrm{M} \mathrm{HCl}$ at room temperature for $20 \mathrm{~min}$ and homogenized by pipetting up and down. After centrifuge, the supernatants were diluted in ELISA buffer and assayed to measure intracellular cAMP levels. The samples of tissues were frozen immediately after collection. Tissues were homogenized in ice-cold 5\% trichloroacetic acid (TCA) and centrifuged at $1500 \boldsymbol{g}$ for $10 \mathrm{~min}$. TCA in supernatant was extracted using watersaturated ether and the aqueous layer was heated to $70^{\circ} \mathrm{C}$ to remove trace amount of ether. The supernatants were assayed directly to measure intracellular cAMP levels. Serum insulin and glucagon were measured using ELISA kits from Crystal Chem (Downers Grove, IL, USA).

\section{Quantitative real-time PCR and immunoblot}

Real-time PCR was performed as previously (Lv et al. 2017). Briefly, total RNA was isolated using TRIzol reagent (Invitrogen) and reverse transcription was done using FastQuant RT kit (Tiangen, Shanghai, China). Real-time PCR was carried out using SuperReal SYBR Green kit (Tiangen) and Lightcycler 96 (Roche). All reactions were performed in duplicate. The amplification efficiency

Published by Bioscientifica Ltd 
for each primer pair and the cycle threshold (Ct) were determined automatically by Lightcycler software (Roche). The fold-change was calculated by the comparative CT $(2-\Delta \Delta C T)$ method against $\beta$-actin (Schmittgen \& Livak 2008). Immunoblot and immunoprecipitation were performed as described (Luan et al. 2014). Briefly, cells were washed with PBS and then resupended in lysis buffer $(150 \mathrm{mM} \mathrm{NaCl}, 1 \%$ Triton-X 100, 1 mM EDTA, $50 \mathrm{mM}$ Tris pH7.5, and protease inhibitor cocktail). For immunoblot, protein content in the supernatant was determined using the Micro BCA protein assay kit (Pierce) and suspended in sample buffer (100 mM Tris, pH 6.8, 4\% SDS, 20\% glycerol, $0.1 \%$ bromophenol blue). The samples were separated on SDS-PAGE gels, transferred, probed with antibodies and visualized using ECL reagents. For immunoprecipitation, the supernatant was precleaned with protein $A / G$ agarose for $30 \mathrm{~min}$ and then incubated overnight on a rocker with primary antibodies at $4^{\circ} \mathrm{C}$, followed by incubation with Protein $A / G$ agarose beads for another $2 \mathrm{~h}$. The immunoprecipitates were extensively washed with lysis buffer and suspended in sample buffer for SDS-PAGE analysis. The immunoreactive bands were quantified with Image-Pro Plus software (Media Cybernetic, Chicago, IL, USA), and quantification using Sigma Plot 8.0 (Systat Software, Chicago, IL, USA) was based on at least three independent experiments.

Primer sequences used for real-time PCR:

Pepck forward 5'-CTGCATAACGGTCTGGACTTC-3'

Pepck reverse 5'-CAGCAACTGCCCGTACTCC-3' G6Pase forward 5'-ACTGTGGGCATCAATCTCCTC-3' G6Pase reverse 5'-CGGGACAGACAGACGTTCAGC-3' $P g c 1 a$ forward 5'-CCCTGCCATTGTTAAGACC -3' $P g c 1 a$ reverse 5'-TGCTGCTGTTCCTGTTTTC -3' $\beta$-Actin forward 5'-GTGACGTTGACATCCGTAAAGA-3' $\beta$-Actin reverse 5'-GCCGGACTCATCGTACTCC-3' Aox forward 5'-AGTTCCATGACCCATCTCTGTC-3' Aox reverse 5'-CAGCAACTGCCCGTACTCC-3' Cpt1a forward 5'-CTCCGCCTGAGCCATGAAG-3' Cpt1a reverse 5'-CACCAGTGATGATGCCATTCT-3' Mcad forward 5'-AGGGTTTAGTTTTGAGTTGACGG-3' Mcad reverse 5'-CCCCGCTTTTGTCATATTCCG-3' Ppara forward 5'-AGAGCCCCATCTGTCCTCTC-3' Ppara reverse 5'-ACTGGTAGTCTGCAAAACCAAA-3' Cyp4a10 forward 5'-TTCCCTGATGGACGCTCTTTA-3' Сур4a10 reverse 5'-GCAAACCTGGAAGGGTCAAAC-3' Cyp4a14 forward 5'-TTTAGCCCTACAAGGTACTTGGA-3' Суp4a14 reverse 5'-GCAGCCACTGCCTTCGTAA-3' $\mathrm{Hmgcl}$ forward 5'-CAGGTGAAGATCGTGGAAGTC-3' $\mathrm{Hmgcl}$ reverse 5'-GGAGCCCTGCTTCGGAAAC-3'
Hmgcs2 forward 5'-GAAGAGAGCGATGCAGGAAAC-3' Hmgcs2 reverse 5'-GTCCACATATTGGGCTGGAAA-3'

\section{Luciferase reporter assay}

Primary hepatocytes were infected with $1 \mathrm{pfu} / \mathrm{cell}$ of Ad-G6Pase-luc or Ad-Aox-luc adenovirus together with Ad-RSV- $\beta$-gal adenovirus for $24 \mathrm{~h}$ and luciferase assays were performed using Promega GloMax96 system according to the manufacturer's instruction (Luan et al. 2014). $\beta$-Gal assay was used to normalize the expression levels.

\section{Liver histological analysis}

Sections $(5 \mu \mathrm{m})$ of formalin-fixed paraffin-embedded mouse liver were used for haematoxylin and eosin (H\&E) staining. Livers embedded in optimal cutting temperature compound (Tissue-Tek, Laborimpex) were used for Oil Red O staining to assess hepatic steatosis.

\section{Glucose tolerance test (GTT) and insulin tolerance test (ITT)}

For glucose tolerance testing, mice were fasted for $16 \mathrm{~h}$, and then injected intraperitoneally with glucose $(1.5 \mathrm{~g} / \mathrm{kg})$. For insulin tolerance testing, mice were fasted for $2 \mathrm{~h}$, and then injected intraperitoneally with insulin (Humulin; 1 U/kg). Blood was collected from the tail vein at indicated times and glucose levels were measured using a One Touch Ultra Glucometer (Johnson \& Johnson).

\section{Statistical analysis}

All studies were performed on at least three independent occasions. Results are reported as mean \pm S.E.M. Differences between two groups were assessed using unpaired Student's $t$ test. Data involving more than two groups were assessed by analysis of variance (ANOVA) with Bonferroni post hoc test. A $P$-value of $<0.05$ was considered statistically significant.

\section{Results}

\section{Glucagon differently stimulates gluconeogenesis and fatty acid oxidation}

To monitor glucagon's effect on hepatic gluconeogenesis and fatty acid oxidation in vivo, we delivered G6Paseluc or Aox-luc adenovirus in mouse liver via tail vein

Published by Bioscientifica Ltd. 
injection and imaged their luciferase reporter activities, respectively, under fasting conditions. G6Pase-luc activity but not Aox-luc activity increased remarkably in the liver after $12 \mathrm{~h}$ fasting (Fig. 1A). On the contrary, Aox-luc activity but not G6Pase-luc activity increased after $48 \mathrm{~h}$ fasting (Fig. 1A). While $12 \mathrm{~h}$ fasting increased serum glucagon and cAMP levels as expected, $48 \mathrm{~h}$ fasting further boosted their secretion (Fig. 1B). Meanwhile, serum triacylglycerol levels were further decreased in $48 \mathrm{~h}$ fasted mice in comparison with $12 \mathrm{~h}$ fasted mice; while ketone bodies increased more dramatically in $48 \mathrm{~h}$ fasted mice in comparison with $12 \mathrm{~h}$ fasted mice (Fig. 1B). Similarly, the expression of endogenous gluconeogenic genes including Pepck, G6Pase and Peroxisome proliferatoractivated receptor $\gamma$ coactivator $1-a(P g c 1 a)$ and fatty acid oxidation genes including Cpt1a, Aox and Mcad was also differently induced by fasting in the liver (Fig. 1C).
Furthermore, exposure to glucagon increased the expression of CREB target genes including Pepck, G6Pase, Insulin receptor substrate 2 (Irs2), Nuclear receptor subfamily 4 group a member 2 (Nr4a2) and Activating transcription factor 3 (Atf3) in primary hepatocytes within $4 \mathrm{~h}$ but less so after 16h (Supplementary Fig. 1A and B, see section on supplementary data given at the end of this article). By contrast, the expression of PPAR $\alpha$ target genes including Cpt1a, Aox, 3-Hydroxy-3-methylglutaryl-CoA synthase 2 (Hmgcs2), Mcad and Fibroblast growth factor 21 (Fgf21) was low at early time $(4 \mathrm{~h})$ but increased dramatically during late time (16h and 24h) (Supplementary Fig. 1C and D). Consistently, short-time treatment of glucagoninduced G6Pase-luc activity but not Aox-luc activity, while long-time treatment of glucagon greatly induced Aox-luc activity in primary hepatocytes (Supplementary Fig. 1E).
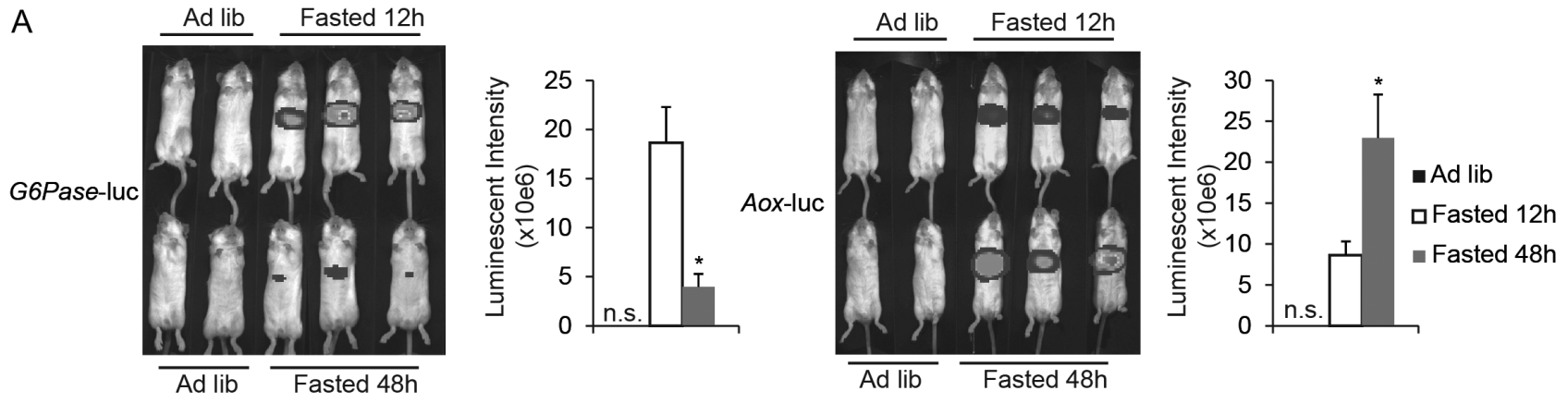

B
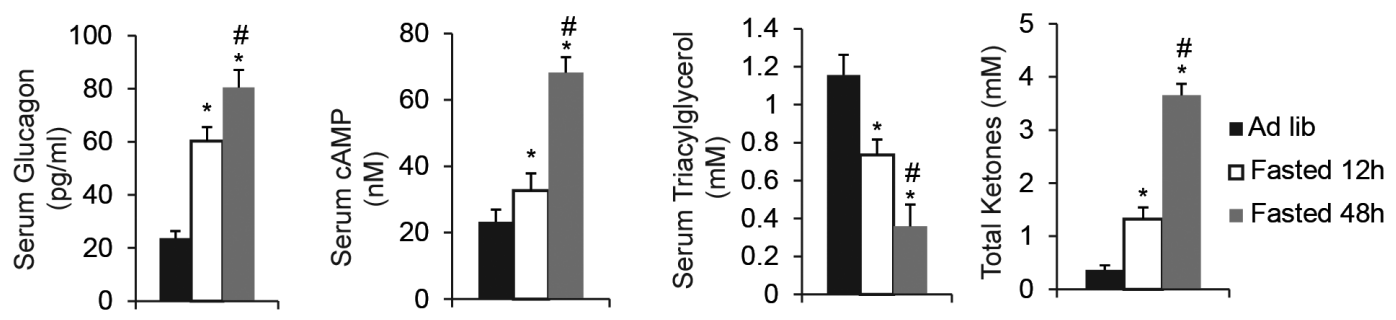

C
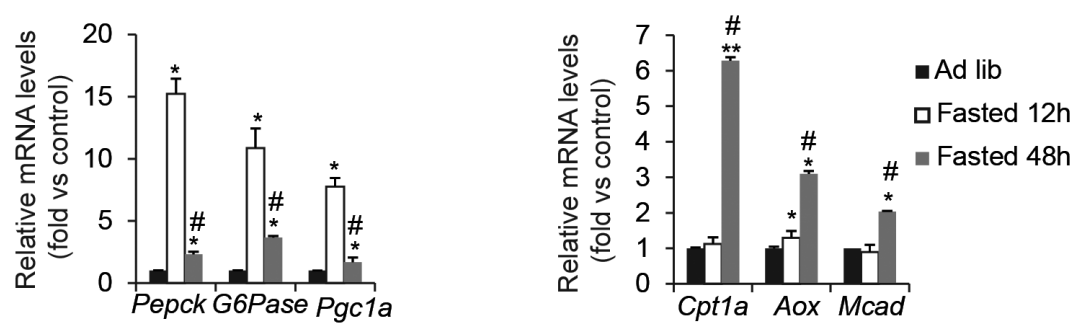

\section{Figure 1}

Glucagon differently stimulates gluconeogenesis and fatty acid oxidation pathway. (A) Effect of short-term and long-term fasting on hepatic G6Pase luciferase reporter activity as well as Aox luciferase reporter activity in mouse liver. Significance was determined by Student's $t$ test (* $P<0.05$ compared with $12 \mathrm{~h}$ fasted mice, $n=8$ ). (B) Effect of short-term and long-term fasting on serum amounts of glucagon, cAMP, triacylglycerol and ketones. Significance was determined by one-way ANOVA ( ${ }^{*}<0.05$ compared with ad libitum mice; $\#<0.05$ compared with $12 \mathrm{~h}$ fasted mice, $n=8$ ). (C) Effect of short-term and long-term fasting on mRNA amounts for gluconeogenic genes including Pepck, G6Pase and Pgc1a and fatty acid oxidation genes including Cpt1a, Aox and Mcad in mouse liver. Significance was determined by one-way ANOVA (*P<0.05, **P<0.01 compared with ad libitum mice; $\# P<0.05$ compared with $12 \mathrm{~h}$ fasted mice, $n=8$ ). 
Intracellular and extracellular cAMP stimulates gluconeogenesis and fatty acid oxidation, respectively

Binding of glucagon to its receptor leads to the activation of stimulatory G protein (Gs) and elevation of intracellular cAMP levels resulting from activation of adenylyl cyclase. In the meantime, cAMP could also be secreted out of the cells and function as a paracrine or endocrine molecule (Northrop \& Parks 1964, Ahloulay et al. 1996). Exposure of primary hepatocytes to glucagon triggered a rapid increase in intracellular cAMP levels at early times and increased extracellular cAMP levels at late times, which correlates well with glucagon's effect on gluconeogenic and fatty acid oxidation gene expression (Fig. 2A and Supplementary Fig. 2A). We wondered whether the slow accumulation of extracellular cAMP accounted for the delayed kinetics of fatty acid oxidation gene expression, while intracellular cAMP mainly functioned through induction of gluconeogenesis at early times. We increased intracellular and extracellular cAMP levels by exposure of primary hepatocytes to 3-Isobutyl-1-Methylxanthine (IBMX, a board-spectrum phosphodiesterase inhibitor) (Fig. 2B and Supplementary Fig. 2B). IBMX greatly increased intracellular and extracellular cAMP levels after glucagon treatment (Fig. 2B and Supplementary Fig. 2B). The expression of Aox and Cpt1a together with G6Pase and Pepck was enhanced by IBMX treatment (Fig. 2C and Supplementary Fig. 2C). Similar results were obtained when primary hepatocytes were infected with adenovirus encoding adenylyl cyclase 6 (Ad-AC6) (Fig. 2D, E and Supplementary Fig. 2D, E).

MRP4 has been reported to mediate the efflux of cAMP (Godinho et al. 2015). Indeed, when long-term glucagon-stimulated cAMP export in primary hepatocytes was blocked by probenecid (a reported MRP4 inhibitor), extracellular cAMP levels were dramatically lower (Fig. 2F), while intracellular cAMP levels were enhanced (Supplementary Fig. 2F). Consistently, chronic glucagonstimulated Aox and Cpt1a expression was blocked by probenecid (Fig. 2G), while G6Pase and Pepck expression was increased (Supplementary Fig. 2G). Furthermore, when hepatic MRP4 was knocked down by adenovirus mediated MRP4 RNAi (Ad-MRP4i), extracellular cAMP as well as chronic glucagon-stimulated Aox and Cpt1a expression was dramatically downregulated (Fig. $2 \mathrm{H}$ and I), while intracellular cAMP as well as G6Pase and Pepck expression were upregulated (Supplementary Fig. 2H, I and J). Further, inhibition of glucagon-stimulated Aox and Cpt1a expression by probenecid was lost in Ad-MRP4i infected cells (Supplementary Fig. 2K). These results indicate that extracellular cAMP mediates glucagon-stimulated fatty acid oxidation genes expression. To directly test the role of extracellular cAMP, primary hepatocytes were treated with increasing concentrations $(10,50$, or $100 \mu \mathrm{mol} / \mathrm{L})$ of cAMP with or without glucagon. Consequent expression of Aox, Cpt1a and Mcad increased in a dose-dependent manner (Fig. 2J). Collectively, these data show that extracellular cAMP secreted from hepatocytes mediates glucagon's late phase effect on fatty acid oxidation genes expression.

\section{Extracellular cAMP activates AMPK to promote PPAR $\alpha$ activation}

The extracellular cAMP-adenosine pathway has been shown to be present in multiple tissues (Rosenberg et al. 1994, Dubey et al. 1996, 2000, Jackson \& Mi 2000). Extracellular cAMP is metabolized to AMP and adenosine in plasma membranes by ecto-phosphodiesterase and 5'-nucleotidase (5'-NT), respectively (Jackson 1991). Based on the ability for adenosine to activate AMPK kinase through adenosine transporter CNT2 (Aymerich et al. 2006), we examined whether extracellular cAMP was able to activate this pathway in primary hepatocytes. After $24 \mathrm{~h}$ cAMP exposure in primary hepatocytes, phosphorylation of AMPK increased in a concentration dependent manner (Fig. 3A). Consistent with the role of glucagon on cAMP efflux, chronic treatment with glucagon also increased phosphorylation of AMPK (Fig. 3B); this effect was blocked by either probenecid or Ad-MRP4i infection (Fig. 3C). Furthermore, $\alpha, \beta$-methylene adenosine 5-diphosphate (AMPCP, a 5'-NT inhibitor), S-(4-nitrobenzyl)-6-thioinosine (NBTI, an adenosine concentrative transporter CNT2 inhibitor), but not 1, 3-dipropyl-8-p-sulfophenylxanthine (DPSPX, a pan adenosine receptor antagonist) ameliorated glucagon's effect on AMPK phosphorylation (Fig. 3D). Exposure of primary hepatocytes to 5-Aminoimidazole4-carboxamide1- $\beta$-D-ribofuranoside (AICAR, an AMPK activator) mimicked the effect of extracellular cAMP on Aox and Cpt1a expression (Fig. 3E). These results suggest that extracellular cAMP-adenosine pathway activates AMPK through adenosine transporter but not adenosine receptor in hepatocytes.

To test the requirement of AMPK for the effect of extracellular cAMP on fatty acid oxidation genes expression, primary hepatocytes were incubated with compound C (an AMPK inhibitor). Compound C inhibited glucagon or cAMP-induced Aox and Cpt1a expression (Fig. 3F). Consistent with the influence on AMPK phosphorylation, AMPCP and NBTI but not DPSPX

Published by Bioscientifica Ltd. 
B

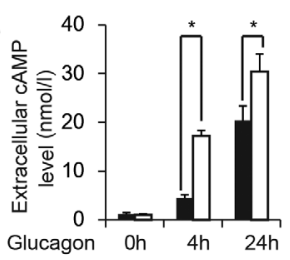

D

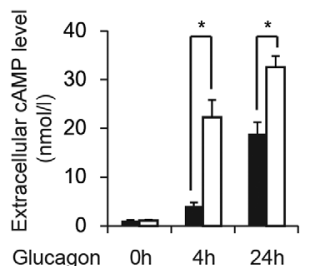

$\mathrm{F}$

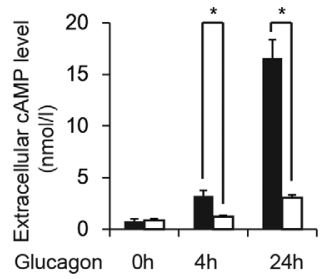

$\mathrm{H}$

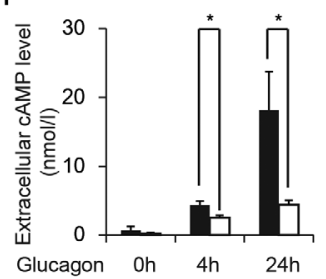

$J$

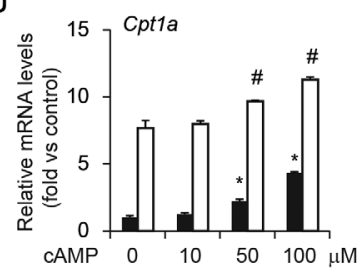

A

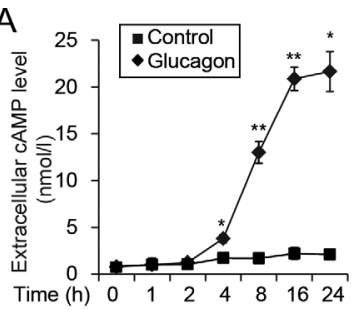

C $\quad$ Control aIBMX
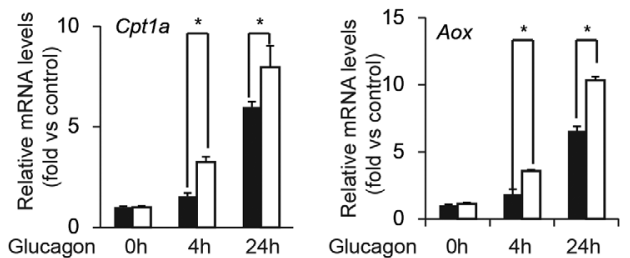

E $\square$ Ad-GFP $\square$ Ad-AC6

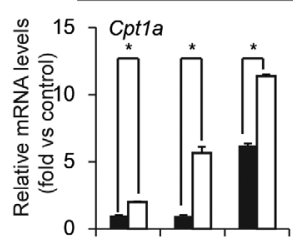

Glucagon $0 \mathrm{~h} \quad 4 \mathrm{~h} \quad 24 \mathrm{~h}$

G Control aProbenecid
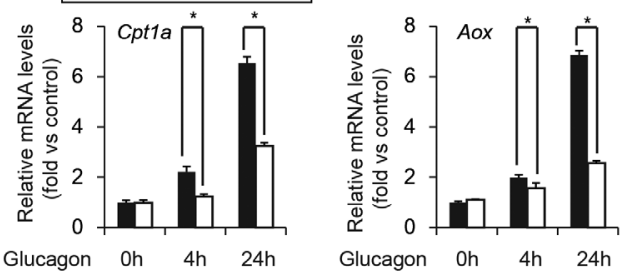

I
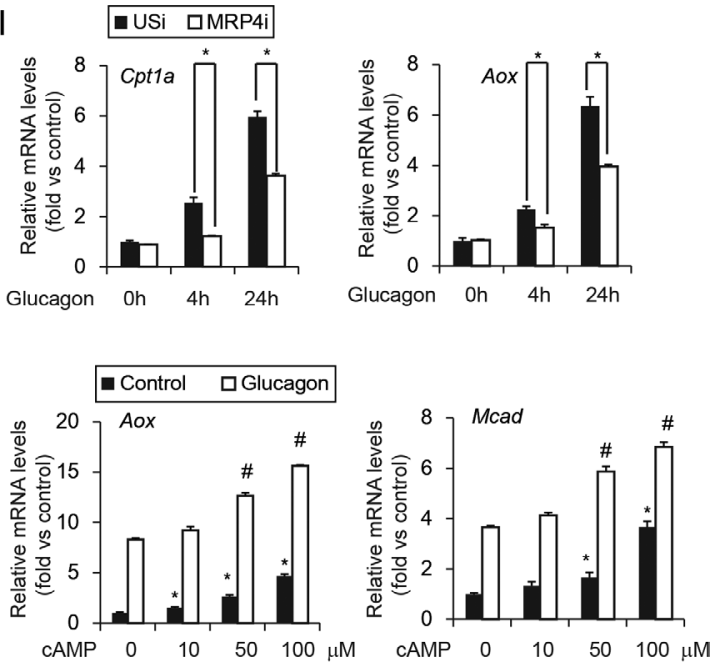

Figure 2

Extracellular CAMP stimulates hepatic fatty acid oxidation. (A) Effect of glucagon $(20 \mathrm{nmol} / \mathrm{L})$ stimulation on extracellular cAMP levels at different time point in primary hepatocytes. Significance was determined by one-way ANOVA ( $P<0.05, * * P<0.01$ compared with respective controls, $n=6)$. (B) Effect of IBMX $(0.1 \mathrm{mmol} / \mathrm{L})$ exposure on glucagon-induced extracellular cAMP levels at different time point in primary hepatocytes. Primary hepatocytes were pretreated with IBMX for $1 \mathrm{~h}$ and followed by glucagon stimulation for indicated times. Significance was determined by Student's $t$ test $\left({ }^{*} P<0.05\right.$ compared between indicated groups, $n=6$ ). (C) Effect of IBMX $(0.1 \mathrm{mmol} / \mathrm{L})$ exposure on glucagon-induced Cpt1a and Aox mRNA amounts at indicated time in primary hepatocytes. Significance was determined by Student's $t$ test ( $P<0.05$ compared between indicated groups, $n=6$ ). (D) Effect of Ad-AC6 on glucagon-induced extracellular CAMP levels. Primary hepatocytes were infected with Ad-GFP or Ad-AC6 for $24 \mathrm{~h}$ and followed by glucagon stimulation for indicated times. Significance was determined by Student's $t$ test $(* P<0.05$ compared between indicated groups, $n=6$ ). (E) Effect of Ad-AC6 on glucagon-induced Cpt1a and Aox mRNA amounts at indicated time in primary hepatocytes. Significance was determined by Student's $t$ test $(* P<0.05$ compared between indicated groups, $n=6$ ). (F) Effect of probenecid $(500 \mu \mathrm{mol} / \mathrm{L})$ exposure on glucagon-induced extracellular CAMP levels at different time point in primary hepatocytes. Primary hepatocytes were pretreated with probenecid for $1 \mathrm{~h}$ and followed by glucagon stimulation for indicated times.

Significance was determined by Student's $t$ test ( $P<0.05$ compared between indicated groups, $n=6)$. (G) Effect of probenecid $(500 \mu \mathrm{mol} / \mathrm{L})$ exposure on glucagon-induced Cpt1a and Aox mRNA amounts at indicated time in primary hepatocytes. Significance was determined by Student's $t$ test ( ${ }^{*} P<0.05$ compared between indicated groups, $n=6)$. (H) Effect of Ad-MRP4i on glucagon-induced extracellular cAMP levels. Primary hepatocytes were infected with Ad-USi or Ad-MRP4i for $48 \mathrm{~h}$ and followed by glucagon stimulation for indicated times. Significance was determined by Student's $t$ test $(* P<0.05$ compared between indicated groups, $n=6$ ). (I) Effect of Ad-MRP4i on glucagon-induced Cpt1a and Aox mRNA amounts at indicated time in primary hepatocytes. Significance was determined by Student's $t$ test ( ${ }^{*} P<0.05$ compared between indicated groups, $n=6)$. (J) Effect of CAMP $(10,50$, or $100 \mu \mathrm{mol} / \mathrm{L})$ exposure on glucagon-induced Cpt1a, Aox and Mcad mRNA amounts in primary hepatocytes. Primary hepatocytes were pretreated with indicated amount of CAMP for $1 \mathrm{~h}$ and followed by control or glucagon stimulation for $24 \mathrm{~h}$. Significance was determined by one-way ANOVA ( ${ }^{*} P<0.05$ compared with the control only; $\# P<0.05$ compared with glucaon only, $n=6$ ). http://joe.endocrinology-journals.org DOI: 10.1530/JOE-16-0649
๑ 2017 Society for Endocrinology Printed in Great Britain 
A

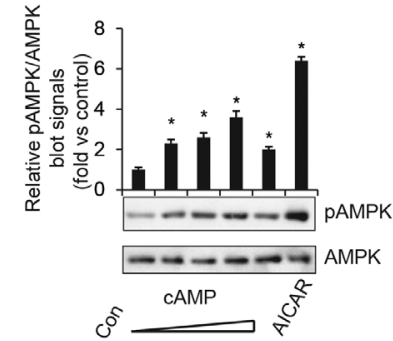

C

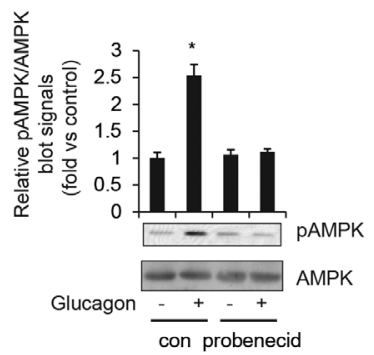

D

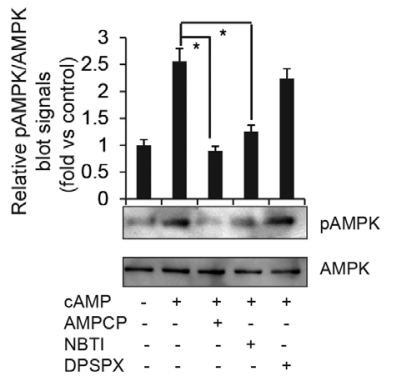

$\mathrm{F}$

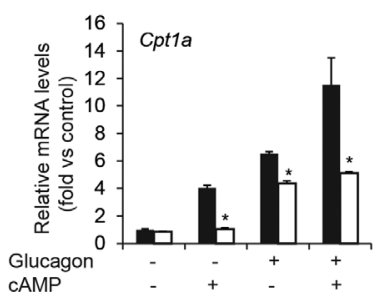

G

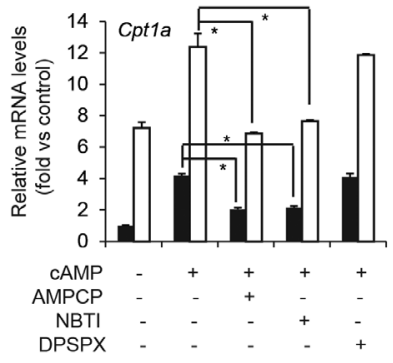

B Glucagon - - - + +
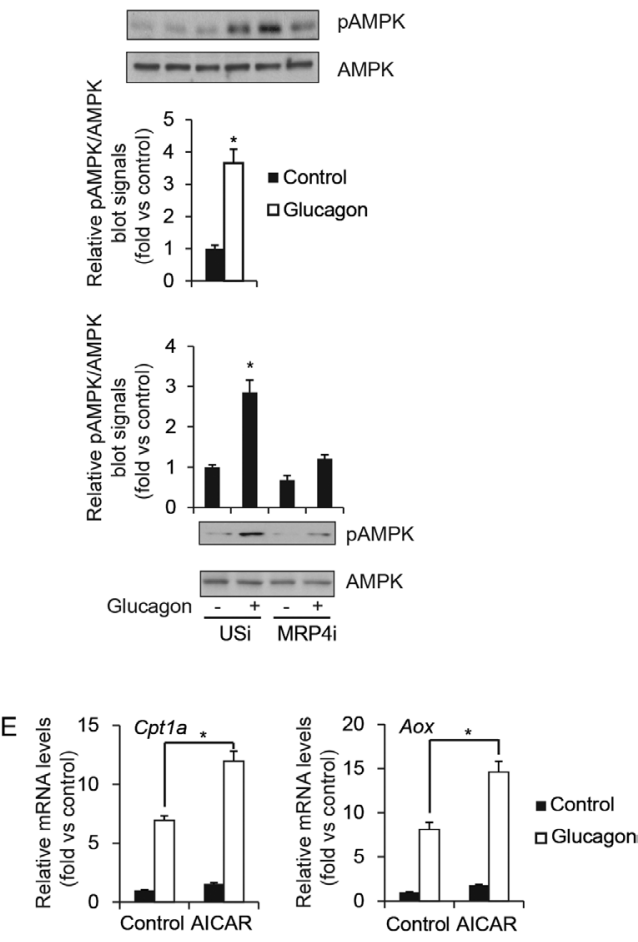

Figure 3

Extracellular cAMP activates AMPK. (A) Immunoblot showing effects of $24 \mathrm{~h}$ cAMP $(10,50,100$ or $200 \mu \mathrm{mol} / \mathrm{L})$ or $2 \mathrm{~h} \mathrm{AICAR}(500 \mu \mathrm{mol} / \mathrm{L})$ treatment on AMPK phosphorylation in primary hepatocytes. Immunoblot intensities for pAMPK/AMPK were quantitated. Significance was determined by one-way ANOVA ( ${ }^{*} P<0.05$ compared with control, $n=4)$. (B) Immunoblot showing effects of $24 \mathrm{~h}$ glucagon $(20 \mathrm{nmol} / \mathrm{L})$ treatment on AMPK phosphorylation in primary hepatocytes. Immunoblot intensities for PAMPK/AMPK were quantitated. Significance was determined by Student's $t$ test $\left({ }^{*} P<0.05\right.$ compared with control, $n=4)$. (C) Immunoblot showing effects of probenecid $(500 \mu \mathrm{mol} / \mathrm{L})$ or Ad-MRP4i treatment on AMPK phosphorylation in primary hepatocytes. Primary hepatocytes were pretreated with probenecid for $1 \mathrm{~h}$ and followed by glucagon stimulation for $24 \mathrm{~h}$ or primary hepatocytes were infected with Ad-USi or Ad-MRP4i for $48 \mathrm{~h}$ and followed by glucagon stimulation for $24 \mathrm{~h}$. Immunoblot intensities for PAMPK/AMPK were quantitated. Significance was determined by one-way ANOVA ( $P<0.05$ compared with respective controls, $n=4)$. (D) Immunoblot showing effects of AMPCP $(0.1 \mathrm{mmol} / \mathrm{L})$, NBTI $(10 \mu \mathrm{mol} / \mathrm{L})$ or DPSPX $(10 \mathrm{nmol} / \mathrm{L})$ on CAMP $(100 \mu \mathrm{mol} / \mathrm{L})$-induced AMPK phosphorylation in primary hepatocytes.

Primary hepatocytes were pretreated with indicated reagents for $1 \mathrm{~h}$ and followed by glucagon stimulation for $24 \mathrm{~h}$. Immunoblot intensities for PAMPK/AMPK were quantitated. Significance was determined by one-way ANOVA $(* P<0.05$ compared between indicated groups, $n=4)$. (E) Effect of $4 \mathrm{~h} \mathrm{AICAR}(500 \mu \mathrm{mol} / \mathrm{L})$ exposure on glucagon-induced Cpt1a and Aox mRNA amounts in primary hepatocytes. Significance was determined by Student's $t$ test $\left({ }^{*} P<0.05\right.$ compared between indicated groups, $n=4)$. (F) Effect of compound $C$ $(50 \mu \mathrm{mol} / \mathrm{L})$ exposure on CAMP $(100 \mu \mathrm{mol} / \mathrm{L})$-induced Cpt1a and Aox mRNA amounts in primary hepatocytes. Primary hepatocytes were pretreated with compound $\mathrm{C}$ for $1 \mathrm{~h}$ and followed by CAMP or glucagon stimulation for $24 \mathrm{~h}$. Significance was determined by one-way ANOVA ( $* P<0.05$ compared with respective controls, $n=4)$. (G) Effect of AMPCP $(0.1 \mathrm{mmol} / \mathrm{L}), \mathrm{NBTI}(10 \mu \mathrm{mol} / \mathrm{L})$ or DPSPX $(10 \mathrm{nmol} / \mathrm{L})$ exposure on CAMP $(100 \mu \mathrm{mol} / \mathrm{L})$ or glucagon ( $20 \mathrm{nmol} / \mathrm{L})$-induced Cpt1a and Aox mRNA amounts in primary hepatocytes. Primary hepatocytes were pretreated with indicated reagents for $1 \mathrm{~h}$ and followed by CAMP or glucagon stimulation for $24 \mathrm{~h}$. Significance was determined by one-way ANOVA ( $* P<0.05$ compared between indicated groups, $n=4)$.

abolished the effect of cAMP and glucagon on Aox and Cpt1a expression (Fig. 3G and Supplementary Fig. 3).

AMPK is a highly conserved energy sensor that specifically phosphorylates substrates with a consensus motif of (L/M/I)-X-R/K-X-X-(S/T)-X-X-X-L (Gwinn et al. 2008). PPAR $\alpha$ master regulator of fatty acid oxidation contains a conserved AMPK phosphorylation motif (Ser452) (Fig. 4A). We hypothesized that AMPK might increase fatty acid oxidation genes expression through direct phosphorylation of PPAR $\alpha$. Exposure of primary hepatocytes to AICAR greatly increased ser/ thr phosphorylation of endogenous PPAR $\alpha$ (Fig. 4B). http://joe.endocrinology-journals.org DOI: 10.1530/JOE-16-0649
(C) 2017 Society for Endocrinology Printed in Great Britain 
To determine that the phosphorylation of PPAR $\alpha$ was dependent on the AMPK consensus site, HEK293T cells were transfected with WT PPAR $\alpha$ or PPAR $\alpha$ S452A with constitutively active form of AMPK (AMPK CA, AMPK T172D). AMPK consensus site (S452) mutation completely disrupted PPAR $\alpha$ phosphorylation by AMPK CA (Fig. 4C). Further, AICAR or cAMP was able to induce AMPK-mediated phosphorylation of PPAR $\alpha$ but not PPAR $\alpha$ mutant (S452A, Fig. 4D). Expression of constitutively active AMPK (AMPK CA) promoted WT PPAR $\alpha$ activity but not PPAR $\alpha$ S452A activity in inducing Aox-luc reporter activity (Fig. 4E) in primary hepatocytes. Consistently, when primary hepatocytes were expressed with PPAR $\alpha$ or PPAR $\alpha 452 \mathrm{~A}$ using adenovirus, the effect of cAMP or AICAR on glucagon-induced Aox and Cpt1a expression was further improved by PPAR $\alpha$ but not PPAR $\alpha$ mutant (S452A) (Fig. 4F).

To demonstrate whether PPAR $\alpha$ is required for the effects of extracellular cAMP on fatty acid oxidation genes expression, primary hepatocytes were either infected with PPAR $\alpha$ RNAi adenovirus (Ad-PPAR $\alpha$ i) or incubated with $10 \mu \mathrm{M}$ of PPAR $\alpha$ antagonist GW6471 and the effect of cAMP on glucagon-induced Aox and Cpt1a expression was largely abolished (Supplementary Fig. 4A, B and C), suggesting a critical role of PPAR $\alpha$ in cAMP-mediated fatty acid oxidation genes expression.

\section{Extracellular CAMP maintains hepatic lipid homeostasis under fasted stage}

The regulation of PPAR $\alpha$ by extracellular cAMP in primary hepatocytes suggests that modulation of extracellular cAMP may influence hepatic lipid homeostasis in vivo. It is reported that prolonged fasting induces lipids deposition in the liver (Li et al. 2014), prompting us to evaluate the function of extracellular cAMP on lipid homeostasis under fasted state. Indeed, 6 days of intravenous injection of cAMP decreased triacylglycerol and NEFA levels in serum and liver, and increased serum ketone bodies after $24 \mathrm{~h}$ fasting (Fig. 5A). Although blood glucose levels remained unchanged after cAMP injection, insulin levels decreased dramatically in cAMP injected mice, suggesting improved insulin sensitivity (Fig. 5A). Mice injected with cAMP showed less lipid accumulation in liver compared with controls (Fig. 5B) and expression of PPAR $\alpha$ target genes known to regulate fatty acid oxidation and ketogenesis were significantly increased in livers of mice injected with cAMP (Fig. 5C). By contrast with the effect of cAMP injection, decreasing extracellular cAMP by Ad-MRP4i infection in liver greatly increased serum and liver triacylglycerol and NEFA levels under $24 \mathrm{~h}$ fasted state (Fig. 5D). Insulin levels were increased while blood glucose remained unchanged (Fig. 5D). Lipid accumulation was also enhanced (Fig. 5E). The expression of hepatic fatty acid oxidation and ketogenesis genes was decreased in Ad-MRP4i injected mice compared with Ad-USi injected mice (Fig. 5F). Consistent with the influence on AMPK phosphorylation and cAMP-induced Aox and Cpt1a expression, intravenous AMPCP injection increased triacylglycerol levels in mouse liver (Supplementary Fig. 5A), while it decreased the expression of hepatic fatty acid oxidation and ketogenesis genes after $24 \mathrm{~h}$ fasting (Supplementary Fig. 5B).

\section{Extracellular CAMP attenuate hepatic steatosis in obese mice}

To further examine the role of extracellular cAMP during in vivo pathogenesis, mice were grouped and fed either a regular diet (RD) or a HFD for 12 weeks. Hepatic cAMP levels were significantly increased in HFD-fed mice compared with RD-fed mice, while serum cAMP levels were contrarily decreased (Fig. 6A), indicating impaired hepatic cAMP efflux. Indeed, expression of hepatic Mrp4 was decreased in HFD-fed mice compared with RD-fed mice (Fig. 6B). Similar results were also observed in $o b / o b$ mice comparing with lean mice (Supplementary Fig. 6). Changes in extracellular cAMP levels in HFD-fed and $o b / o b$ mice indicate the pathophysiological role of extracellular cAMP under diabetic conditions and prompt further investigation into its contribution to obesity-associated hepatic steatosis. Indeed, 6 days of cAMP injection dramatically decreased liver and serum triacylglycerol and NEFA levels in comparison with controls (Fig. 6C). Serum ketone bodies were dramatically increased in mice injected with cAMP compared with controls (Fig. 6C), correlating with increased ketogenesis and fatty acid oxidation by extracellular cAMP in hepatocytes. cAMP injection showed dramatically less lipid accumulation in liver compared with controls evidenced by $\mathrm{H} \& \mathrm{E}$ and Oil Red $\mathrm{O}$ staining (Fig. 6D). Consistently, expression of PPAR $\alpha$ target genes known to regulate fatty acid oxidation and ketogenesis were significantly increased in livers of mice injected with cAMP (Fig. 6E). Further, cAMP injection also decreased blood glucose, insulin levels and HFD-induced glucose intolerance and insulin resistance (Fig. 6F and G), indicating insulin-sensitizing effect of cAMP. 


\section{Increasing hepatic Mrp4 expression ameliorates hepatic steatosis caused by high-fat diet}

Based on the observation that hepatic Mrp4 expression was decreased in HFD-fed mice, we hypothesized that increasing hepatic MRP4 expression could ameliorates hepatic steatosis caused by HFD. It has been reported that Mrp4 expression could be regulated by farnesoid X receptor (FXR) (Schuetz et al. 2001), constitutive androstane receptor (CAR) (Aleksunes \& Klaassen 2012) and Nuclear Factor-E2-Related Factor-2 (NRF2) (Maher et al. 2007). Indeed, hepatic mRNA levels of Car and Nrf2 but not $\mathrm{F} x \mathrm{r}$ were dramatically reduced in both HFD-fed mice and $o b / o b$ mice, suggesting their contribution to the reduced Mrp4 expression (Supplementary Fig. 7A and B). Oltipraz (OPZ) has been reported to be an activator of both CAR and NRF2 (Merrell et al. 2008). When HFD-fed mice were injected with OPZ, reduced Mrp4 mRNA levels as well as serum cAMP levels were rescued (Supplementary Fig. 7C and D), indicating that reduced hepatic Car and $\mathrm{Nrf2}$ expression in HFD-fed mice account for the reduced Mrp4 expression and cAMP efflux from the liver. As a result, hepatic triacylglycerol was also decreased in OPZ injected mice (Supplementary Fig. 7E). Additionally, the expression of PPAR $\alpha$ target genes known to regulate fatty acid oxidation and ketogenesis were significantly increased in livers of mice injected with OPZ (Supplementary Fig. 7F). These results suggested that increased Mrp4 expression was able to improve the hepatic steatosis induced by HFD.

\section{Discussion}

Fatty acid oxidation and subsequent ketogenesis is one of the major mechanisms to maintain hepatic lipid homeostasis under fasting conditions. Hormone glucagon has been shown to stimulate ketone body production through activation of PPAR $\alpha$. Studies using glucagon receptor knockout mice and PPAR $\alpha$ knockout mice have demonstrated the central importance of the glucagonPPAR $\alpha$ signaling pathway for the control of hepatic lipid metabolism in response to fasting (Longuet et al. 2008, von Meyenn et al. 2013). However, the molecular basis of this link is still largely undiscovered. In our study, we show that glucagon stimulates PPAR $\alpha$ activity through extracellular cAMP-mediated AMPK phosphorylation, elucidating the signaling cascade that mediates glucagonstimulated PPAR $\alpha$ activation (Fig. 6H). Most importantly, the administration of cAMP in vivo decreased serum and hepatic triacylglycerol, NEFA levels and increased ketone bodies under fasted stage or following exposure to a HFD, while blocking cAMP efflux from liver by MRP4 knockdown leads to hepatic steatosis. Hence, both in vitro and in vivo results implicate an essential physiological role of extracellular cAMP in the control of fasting-enhanced fatty acid oxidation.

It is well documented that glucagon-induced efflux of cAMP is also regulated by insulin (Exton et al. 1971a, Zumstein et al. 1974). Insulin decreases the efflux of cAMP in response to glucagon in hepatocytes (Pilkis et al. 1975, Marchmont \& Houslay 1980). Thus, the level of extracellular cAMP depends on the ratio between glucagon and insulin concentrations in normal condition. However, in obese mice, which are characterized by hyperglucagonemia and hyperinsulinemia, serum cAMP levels were conversely decreased, due to the deceased expression of Mrp4 in liver and probably also due to the hyperinsulinemia-induced degradation. Hence, defective glucagon and insulin action coordinates through extracellular cAMP to cause the dysfunction of hepatic fatty acid oxidation which leads to steatosis in the pathophysiology of type 2 diabetes (Unger \& Cherrington 2012). Taken into consideration the hyperglycemia caused by elevated glucagon-stimulated glucose production and defective insulin mediated suppression of glucose production due to insulin resistance (Edgerton $\&$ Cherrington 2013), our current data thus provide new insight into the understanding of the glucose and lipid defect in subjects with type 2 diabetes through glucagon and insulin together.

Adenosine and its receptors have been shown to play an important role in the pathogenesis of alcoholic fatty liver. Chronic alcohol-stimulated adenosine release stimulates adenosine $A_{1}$ and $A_{2 B}$ receptors, which promote the development of fatty liver. Blockade or deletion of these receptors diminishes hepatic triglyceride accumulation and development of fatty liver (Peng et al. 2009). The function of adenosine and its receptors in nonalcoholic fatty liver is still elusive. Caffeine, a nonselective adenosine receptor antagonist significantly decreases hepatic lipid content in diabetic KK mice (Muroyama et al. 2003, Murosaki et al. 2007). Most importantly, caffeine intake shows a potential protective effect in patients with nonalcoholic fatty liver disease (Birerdinc et al. 2012). Our data also demonstrate that adenosine transporter CNT2 inhibitor NBTI ameliorated glucagon-stimulated fatty acid oxidation genes express. Thus, adenosine receptors may also play a role in the pathogenesis of nonalcoholic fatty liver which will need further investigation. (c) 2017 Society for Endocrinology Printed in Great Britain
Published by Bioscientifica Ltd 
A

AMPK consensus: (L/M/I)-X-R/K-X-X-(S/T)-X-X-X-L

Macaca mulatta 446-I-I-K-K-T-E-S-D-A-A-L-456 Mus musculus 446-V-I-K-K-T-E-S-D-A-A-L-456 Homo sapiens 446-I-I-K-K-T-E-S-D-A-A-L-456

Rattus norvegicus 446-I-I-K-K-T-E-S-D-A-A-L-456 Equus caballus 446-I-I-K-K-T-E-S-D-A-A-L-456 S452
B

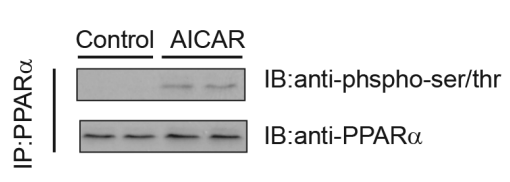

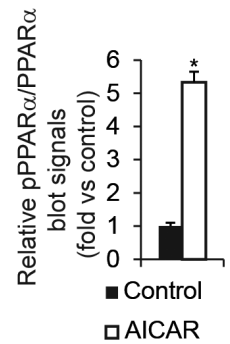

C
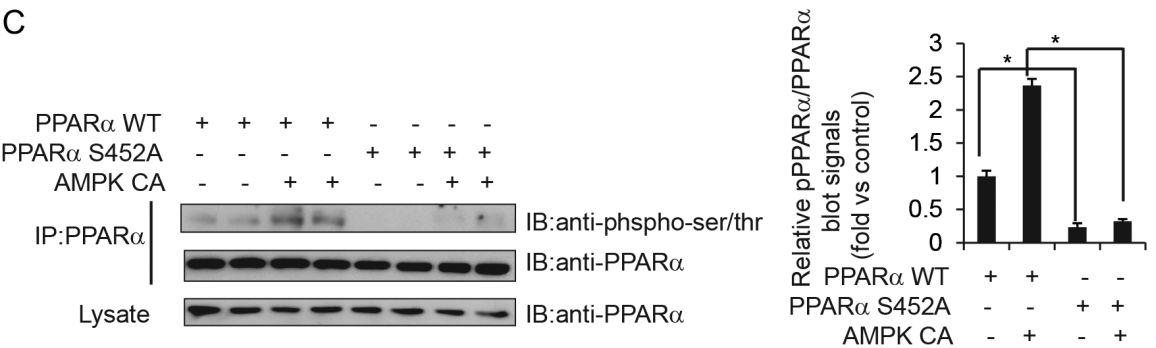

D
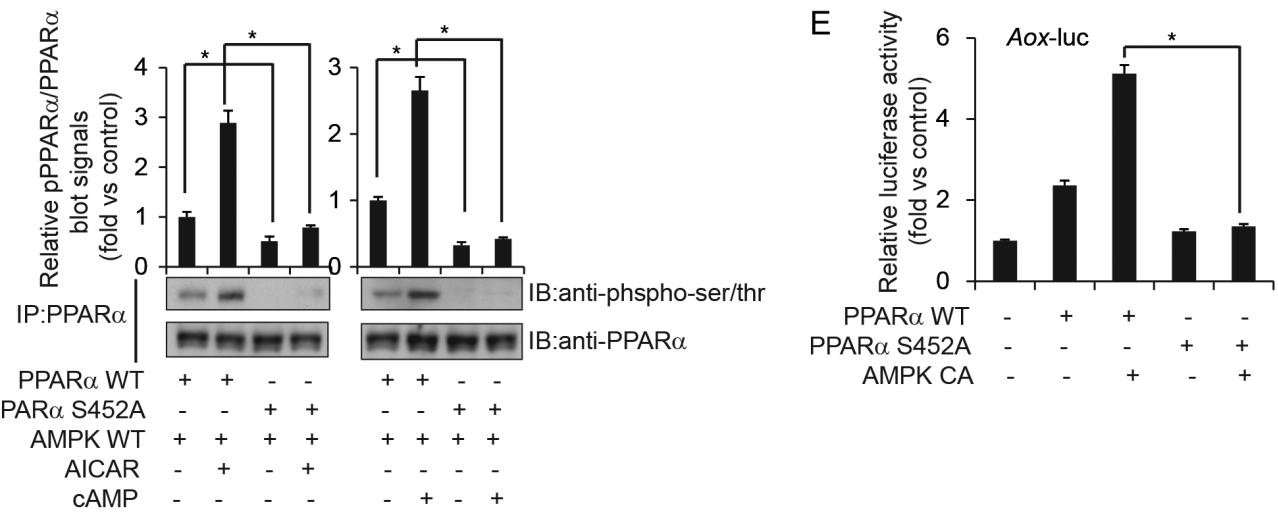

$\mathrm{F}$
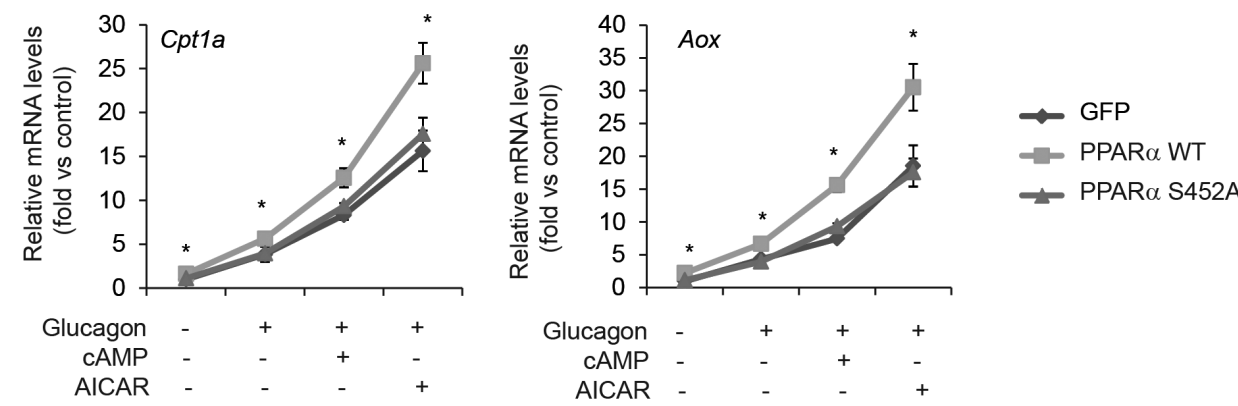

Figure 4

AMPK phosphorylation promotes PPAR $\alpha$ activation. (A) Conserved AMPK consensus site on PPAR $\alpha$. (B) Immunoblot showing effects of $2 \mathrm{~h}$ AICAR $(500 \mu \mathrm{mol} / \mathrm{L})$ treatment on PPAR $\alpha$ phosphorylation in primary hepatocytes. Immunoblot intensities for pPPAR $/$ PPAR $\alpha$ were quantitated. Significance was determined by Student's $t$ test ( ${ }^{*}<0.05$ compared with control, $n=4$ ). (C) Immunoblot showing effect of mutations in the AMPK phosphorylation site (S452A) on PPAR $\alpha$ phosphorylation by AMPK CA in HEK293T cells. HEK293T cells were transfected with indicated plasmid for $24 \mathrm{~h}$. Immunoblot intensities for pPPAR $\alpha$ PPAR $\alpha$ were quantitated. Significance was determined by one-way ANOVA ( ${ }^{*}<0.05$ compared with control in PPAR $\alpha$ WT, $\left.n=4\right)$. (D) Immunoblot showing effect of $2 \mathrm{~h}$ AICAR $(500 \mu \mathrm{mol} / \mathrm{L})$ or $24 \mathrm{~h}$ CAMP $(100 \mu \mathrm{mol} / \mathrm{L})$ treatment on PPAR $\alpha$ or PPAR $\alpha$ S452A phosphorylation by AMPK in HepG2 cells. HepG2 cells were transfected with indicated plasmid for $48 \mathrm{~h}$ before treatment. Immunoblot intensities for pPPAR $\alpha$ PPAR $\alpha$ were quantitated. Significance was determined by one-way ANOVA ( $* P<0.05$, compared between indicated groups, $n=4)$. (E) Effect of wild-type or $S 452 \mathrm{~A}$ mutant PPAR $\alpha$ on Aox-luc reporter activity. Primary hepatocytes were infected with Ad-Aox-luc, Ad-RSV- $\beta$-gal together with Ad-PPAR $\alpha$, Ad-PPAR $\alpha$ S452A and Ad-AMPK CA adenovirus for $24 \mathrm{~h}$. Significance was determined by one-way ANOVA ( ${ }^{*} P<0.05$, compared between indicated groups, $\left.n=6\right)$. Effect of AMPK CA expression was shown. (F) Effect of wild-type or S452A mutant PPAR $\alpha$ on CAMP ( $100 \mu \mathrm{mol} / \mathrm{L})$-induced or AICAR $(500 \mu \mathrm{mol} / \mathrm{L})$-induced Cpt1a and Aox mRNA amounts in primary hepatocytes. Primary hepatocytes were infected with Ad-GFP, Ad-PPAR $\alpha$ or Ad-PPAR $\alpha 452 \mathrm{~A}$ for $24 \mathrm{~h}$. Cells were pretreated with CAMP or AICAR for $1 \mathrm{~h}$ and followed by glucagon stimulation for $24 \mathrm{~h}$. Significance was determined by two-way ANOVA ( $P<0.05$, GFP vs PPAR $\alpha$ WT, $n=6$ ). 
A
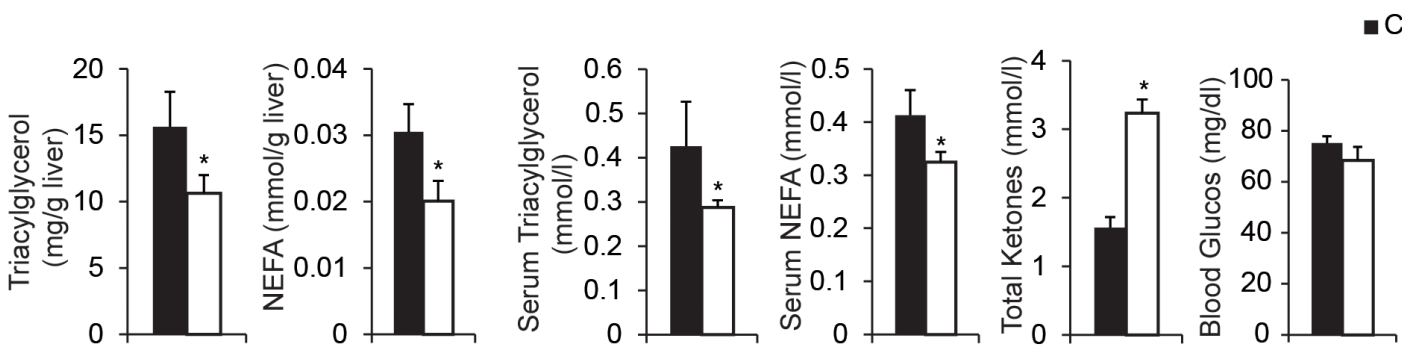

- Control acAMP
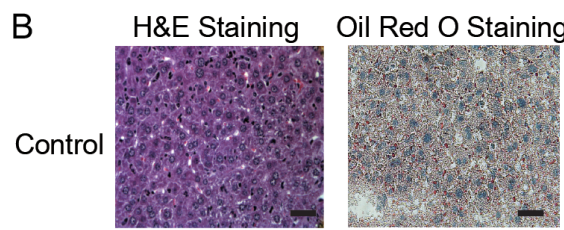

C
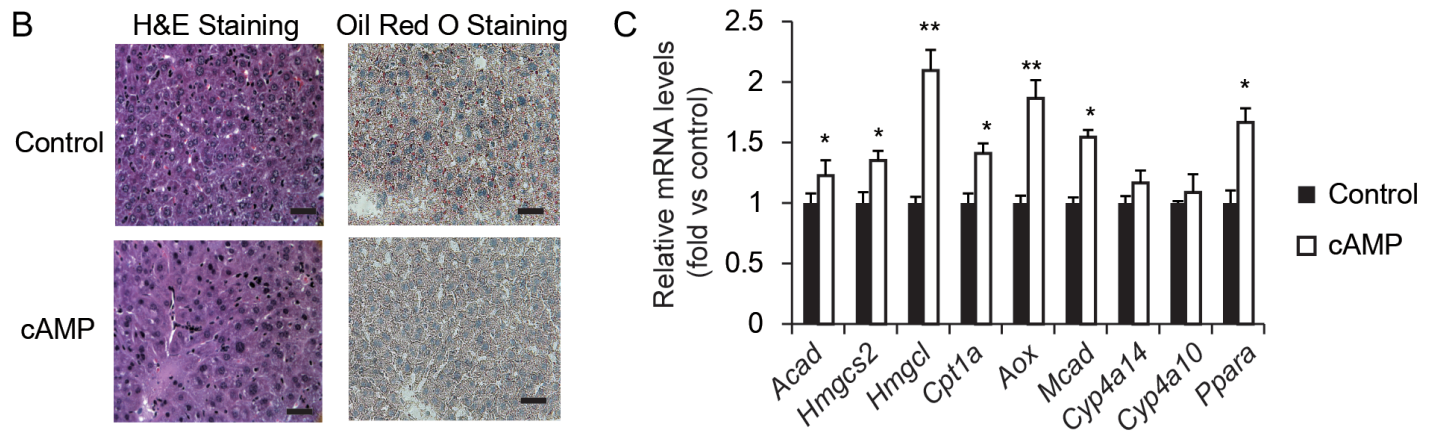

D
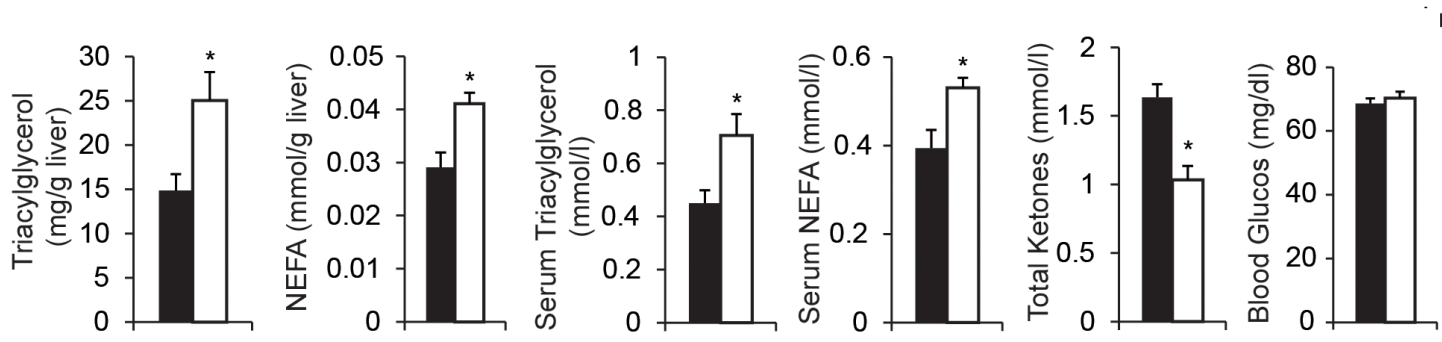

- USi aMRP4i

E
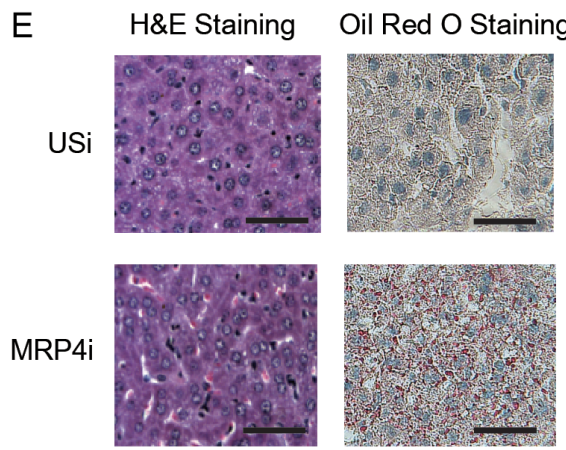

\section{F}

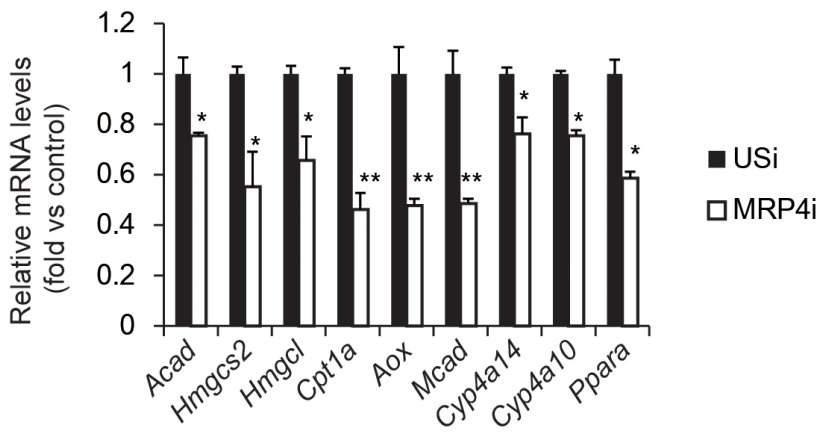

Figure 5

Extracellular CAMP maintains lipid homeostasis under fasted stage. (A) Effect of cAMP (20 mg/kg) injection on hepatic and serum triacylglycerol, NEFA, serum ketones, blood glucose and insulin levels in $24 \mathrm{~h}$ fasted mice. Significance was determined by Student's $t$ test ( $P<0.05$ compared with control, $n=8)$. (B) Representative H\&E and Oil Red O staining of liver from CAMP injected mice (scale bar, $50 \mu \mathrm{m})$. (C) Effect of cAMP (20 mg/kg) injection on hepatic fatty acid oxidation gene expression. Significance was determined by Student's $t$ test (*P<0.05, ** $P<0.01$ compared with control, $n=8$ ). (D) Effect of Ad-MRP4i injection on hepatic and serum triacylglycerol, NEFA, serum ketones, blood glucose and insulin levels in $24 \mathrm{~h}$ fasted mice. Significance was determined by Student's $t$ test ( $P<0.05$ compared with USi, $n=8$ ). (E) Representative H\&E and Oil Red O staining of liver from Ad-MRP4i injected mice (scale bar, $50 \mu \mathrm{m}$ ). (F) Effect of Ad-MRP4i injection on hepatic fatty acid oxidation gene expression. Significance was determined by Student's $t$ test $\left({ }^{*} P<0.05, * * P<0.01\right.$ compared with USi, $\left.n=8\right)$.

AMPK is a key regulator of fatty acid oxidation in liver. Although AICAR (AMPK activation) treatment alone is enough to cause PPAR $\alpha$ phosphorylation, AICAR alone without glucagon is not enough to increase fatty acid oxidation genes expression (Fig. 3E), suggesting other aspects of the glucagon signaling pathway are required.

\begin{tabular}{|lr}
\hline http://joe.endocrinology-journals.org & @ 2017 Society for Endocrinology \\
DOI: $10.1530 / J O E-16-0649$ & Printed in Great Britain
\end{tabular}

Von Meyenn and coworkers have shown that glucagon stimulation induced Lys259 acetylation of Foxa2, which plays an important role in glucagon-stimulated fatty acid oxidation (von Meyenn et al. 2013). Our previous work also pointed out that glucagon could promote fatty acid oxidation through releasing the inhibitory effect of SIK2

Published by Bioscientifica Ltd 
A
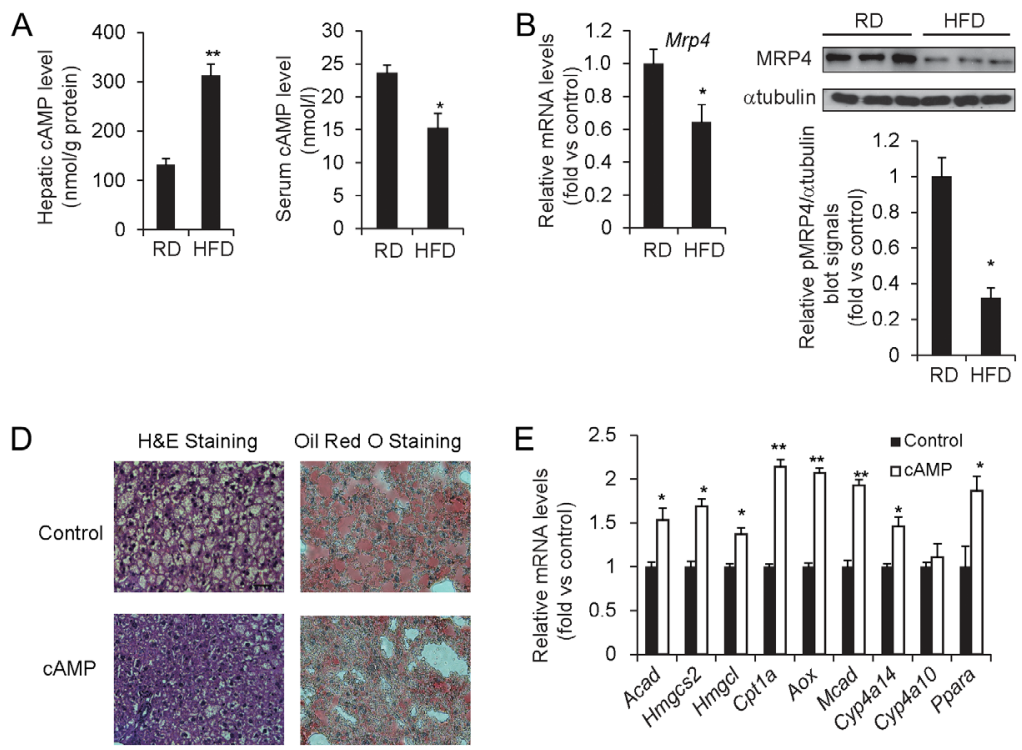

G

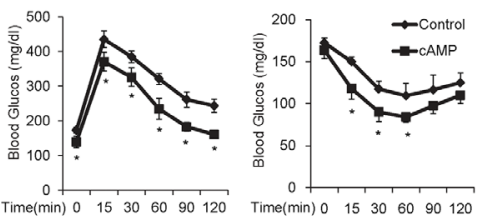

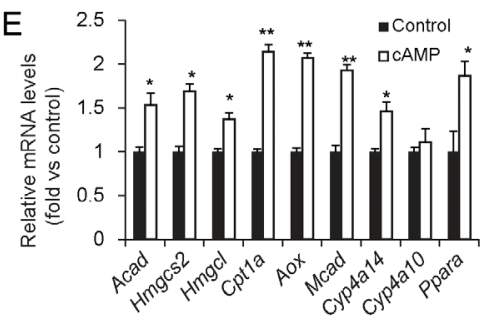

$\mathrm{H}$

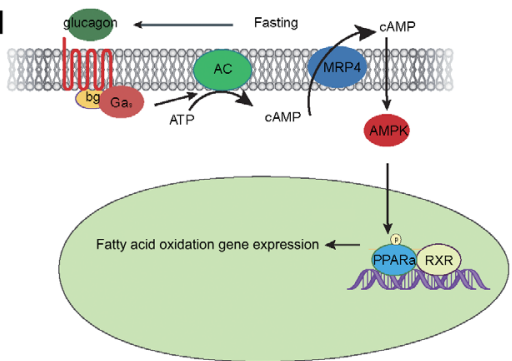

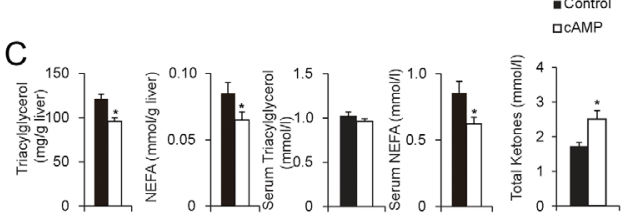

F

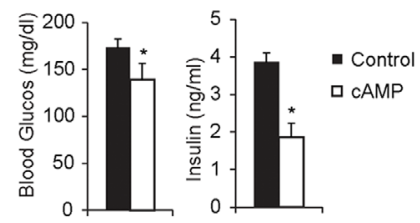

Figure 6

CAMP administration attenuates hepatic steatosis caused by HFD. (A) Hepatic and serum cAMP levels in RD or HFD-fed mice. Significance was determined by Student's $t$ test ( ${ }^{*} P<0.05, * * P<0.01$ compared with RD-fed mice, $n=8$ ). (B) Hepatic Mrp4 mRNA (left) and protein (right) levels in mice fed on RD or

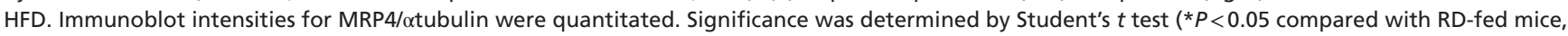
$n=8)$. (C) Effect of CAMP ( $20 \mathrm{mg} / \mathrm{kg}$ ) injection on hepatic and serum triacylglycerol, NEFA and serum ketones levels in HFD-fed mice. Significance was determined by Student's $t$ test ( ${ }^{*} P<0.05$ compared with control, $n=8$ ). (D) Representative H\&E and Oil Red O staining of liver sections from HFD-fed mice injected with CAMP (scale bar, $50 \mu \mathrm{m})$. (E) Effect of CAMP $(20 \mathrm{mg} / \mathrm{kg}$ ) injection on hepatic fatty acid oxidation gene expression. Significance was determined by Student's $t$ test $(* P<0.05, * * P<0.01$ compared with control, $n=8)$. (F) Effect of cAMP ( $20 \mathrm{mg} / \mathrm{kg})$ injection on blood glucose and insulin levels in HFD-fed mice. Significance was determined by Student's $t$ test ( ${ }^{*} P<0.05$ compared with control, $\left.n=8\right)$. (G) Effect of cAMP (20 mg/kg) injection on GTT and ITT in HFD-fed mice. Significance was determined by one-way ANOVA ( $P<0.05$ compared with control mice, $n=8)$. (H) Schematic of proposed mechanism.

on p300, which binds to PPAR $\alpha$ and promotes PPAR $\alpha$ activity (Zhang et al. 2016). Thus, glucagon regulates fatty acid oxidation genes expression and PPAR $\alpha$ activity through multiple mechanisms.

Glucagon and its receptor contributes to the establishment of hyperglycemia and insulin resistance (Unger \& Cherrington 2012, Patarrao et al. 2015) and glucagon receptor antagonists (Sammons \& Lee 2015) as well as antisense oligonucleotides (ASOs) against glucagon receptor (van Dongen et al. 2014) are being assessed for the treatment of T2DM in human; however, the implication that impairment of fatty acid oxidation due to inhibition of hepatic glucagon signaling may precede, and eventually cause, hepatic steatosis suggests limited utility for glucagon antagonism as a potential strategy for T2DM in human. Our data demonstrate that in fasted state, although glucagon action is essential for lipid metabolism, administration of extracellular cAMP may reproduce the effect of glucagon on fatty acid oxidation. Hence, the administration of cAMP in combination with glucagon receptor ASOs or antagonists may serve as a more convincing strategy in clinical use in patients with T2DM.

\section{Supplementary data}

This is linked to the online version of the paper at http://dx.doi.org/10.1530/ JOE-16-0649. http://joe.endocrinology-journals.org DOI: $10.1530 / J O E-16-0649$
() 2017 Society for Endocrinology Printed in Great Britain 


\section{Declaration of interest}

The authors declare that there is no conflict of interest that could be perceived as prejudicing the impartiality of the research reported.

\section{Funding}

This research was supported by grants from 1000 Talents Program for Young Scholars of China to Bing Luan; the National Science Foundation of China (81671110) and Shanghai Rising-Star Program (17QA1402900) to Zhen-Ning Zhang.

\section{Acknowledgements}

The authors thank Dr Marc Montminy and Susan Hedrick (Salk Institute, La Jolla, CA, USA) for discussion and technical support. They thank Dr Jerome $\checkmark$ Karpiak (University of California San Diego School of Medicine, Sanford Consortium for Regenerative Medicine, La Jolla, CA, USA) for Englishlanguage editing.

\section{References}

Ahloulay M, Dechaux M, Hassler C, Bouby N \& Bankir L 1996 Cyclic AMP is a hepatorenal link influencing natriuresis and contributing to glucagon-induced hyperfiltration in rats. Journal of Clinical Investigation 98 2251-2258. (doi:10.1172/JCI119035)

Aleksunes LM \& Klaassen CD 2012 Coordinated regulation of hepatic phase I and II drug-metabolizing genes and transporters using AhR-, CAR-, PXR-, PPARalpha-, and Nrf2-null mice. Drug Metabolism and Disposition 40 1366-1379. (doi:10.1124/ dmd.112.045112)

Altarejos JY \& Montminy M 2011 CREB and the CRTC co-activators: sensors for hormonal and metabolic signals. Nature Reviews Molecular Cell Biology 12 141-151. (doi:10.1038/nrm3072)

Ardaillou N, Placier S, Wahbe F, Ronco P \& Ardaillou R 1993 Release of cyclic nucleotides from the apical and basolateral poles of cultured human glomerular epithelial cells. Experimental Nephrology 1 253-260.

Aymerich I, Foufelle F, Ferre P, Casado FJ \& Pastor-Anglada M 2006 Extracellular adenosine activates AMP-dependent protein kinase (AMPK). Journal of Cell Science 119 1612-1621. (doi:10.1242/ jcs.02865)

Bernal-Mizrachi C, Xiaozhong L, Yin L, Knutsen RH, Howard MJ, Arends JJ, Desantis P, Coleman T \& Semenkovich CF 2007 An afferent vagal nerve pathway links hepatic PPARalpha activation to glucocorticoidinduced insulin resistance and hypertension. Cell Metabolism $\mathbf{5}$ 91-102. (doi:10.1016/j.cmet.2006.12.010)

Birerdinc A, Stepanova M, Pawloski L \& Younossi ZM 2012 Caffeine is protective in patients with non-alcoholic fatty liver disease. Alimentary Pharmacology and Therapeutics 35 76-82. (doi:10.1111/ j.1365-2036.2011.04916.x)

Boumendil-Podevin EF \& Podevin RA 1977 Transport and metabolism of adenosine $3^{\prime}: 5^{\prime}$-monophosphate and N6, O2'-dibutyryl adenosine $3^{\prime}: 5^{\prime}$-monophosphate by isolated renal tubules. Journal of Biological Chemistry 252 6675-6681.

Butcher RW, Baird CE \& Sutherland EW 1968 Effects of lipolytic and antilipolytic substances on adenosine $3^{\prime}, 5^{\prime}$-monophosphate levels in isolated fat cells. Journal of Biological Chemistry 243 1705-1712.

Constantin J, Suzuki-Kemmelmeier F, Yamamoto NS \& Bracht A 1997 Production, uptake, and metabolic effects of cyclic AMP in the bivascularly perfused rat liver. Biochemical Pharmacology 54 1115-1125. (doi:10.1016/S0006-2952(97)00303-1)
Coulson R \& Bowman RH 1974 Excretion and degradation of exogenous adenosine $3^{\prime}, 5^{\prime}$-monophosphate by isolated perfused rat kidney. Life Science 14 545-566. (doi:10.1016/0024-3205(74)90369-5)

Dentin R, Pegorier JP, Benhamed F, Foufelle F, Ferre P, Fauveau V, Magnuson MA, Girard J \& Postic C 2004 Hepatic glucokinase is required for the synergistic action of ChREBP and SREBP-1c on glycolytic and lipogenic gene expression. Journal of Biological Chemistry 279 20314-20326. (doi:10.1074/jbc.M312475200)

Dubey RK, Mi Z, Gillespie DG \& Jackson EK 1996 Cyclic AMP-adenosine pathway inhibits vascular smooth muscle cell growth. Hypertension $\mathbf{2 8}$ 765-771. (doi:10.1161/01.HYP.28.5.765)

Dubey RK, Gillespie DG, Mi Z \& Jackson EK 2000 Cardiac fibroblasts express the cAMP-adenosine pathway. Hypertension 36 337-342. (doi:10.1161/01.HYP.36.3.337)

Edgerton DS \& Cherrington AD 2013 Glucagon's yin and yang effects on hepatic glucose production. Nature Medicine 19 674-675. (doi:10.1038/nm.3202)

Exton JH, Lewis SB, Ho RJ, Robison GA \& Park CR 1971 $a$ The role of cyclic AMP in the interaction of glucagon and insulin in the control of liver metabolism. Annals of the New York Academy of Sciences $\mathbf{1 8 5}$ 85-100. (doi:10.1111/j.1749-6632.1971.tb45239.x)

Exton JH, Robison GA, Sutherland EW \& Park CR 1971 $b$ Studies on the role of adenosine $3^{\prime}, 5^{\prime}$-monophosphate in the hepatic actions of glucagon and catecholamines. Journal of Biological Chemistry 246 6166-6177.

Ford ES, Giles WH \& Mokdad AH 2004 Increasing prevalence of the metabolic syndrome among U.S. adults. Diabetes Care 27 2444-2449. (doi:10.2337/diacare.27.10.2444)

Godinho RO, Duarte T \& Pacini ES 2015 New perspectives in signaling mediated by receptors coupled to stimulatory $\mathrm{G}$ protein: the emerging significance of cAMP e ffl ux and extracellular cAMP-adenosine pathway. Frontiers in Pharmacology 6 58. (doi:10.3389/fphar.2015.00058)

Gwinn DM, Shackelford DB, Egan DF, Mihaylova MM, Mery A, Vasquez DS, Turk BE \& Shaw RJ 2008 AMPK phosphorylation of raptor mediates a metabolic checkpoint. Molecular Cell 30 214-226. (doi:10.1016/j.molcel.2008.03.003)

Hooper AJ, Adams LA \& Burnett JR 2011 Genetic determinants of hepatic steatosis in man. Journal of Lipid Research 52 593-617. (doi:10.1194/ jlr.R008896)

Im SS, Kim MY, Kwon SK, Kim TH, Bae JS, Kim H, Kim KS, Oh GT \& Ahn YH 2011 Peroxisome proliferator-activated receptor $\{$ alpha\} is responsible for the up-regulation of hepatic glucose-6-phosphatase gene expression in fasting and $\mathrm{db} / \mathrm{db}$ Mice. Journal of Biological Chemistry 286 1157-1164. (doi:10.1074/jbc.M110.157875)

Jackson EK 1991 Adenosine: a physiological brake on renin release. Annual Review of Pharmacology and Toxicology 31 1-35. (doi:10.1146/ annurev.pa.31.040191.000245)

Jackson EK \& Mi Z 2000 Preglomerular microcirculation expresses the cAMP-adenosine pathway. Journal of Pharmacology and Experimental Therapeutics 295 23-28.

Li Y, Wong K, Giles A, Jiang J, Lee JW, Adams AC, Kharitonenkov A, Yang Q, Gao B, Guarente L, et al. 2014 Hepatic SIRT1 attenuates hepatic steatosis and controls energy balance in mice by inducing fibroblast growth factor 21. Gastroenterology 146 539.e537-549.e537. (doi:10.1053/j.gastro.2013.10.059)

Liu Y, Dentin R, Chen D, Hedrick S, Ravnskjaer K, Schenk S, Milne J, Meyers DJ, Cole P, Yates J 3rd, et al. 2008 A fasting inducible switch modulates gluconeogenesis via activator/coactivator exchange. Nature 456 269-273. (doi:10.1038/nature07349)

Longuet C, Sinclair EM, Maida A, Baggio LL, Maziarz M, Charron MJ \& Drucker DJ 2008 The glucagon receptor is required for the adaptive metabolic response to fasting. Cell Metabolism 8 359-371. (doi:10.1016/j.cmet.2008.09.008)

Louet JF, Hayhurst G, Gonzalez FJ, Girard J \& Decaux JF 2002 The coactivator PGC-1 is involved in the regulation of the liver carnitine palmitoyltransferase I gene expression by cAMP in combination with http://joe.endocrinology-journals.org

DOI: 10.1530/JOE-16-0649
๑) 2017 Society for Endocrinology Printed in Great Britain 
HNF4 alpha and cAMP-response element-binding protein (CREB). Journal of Biological Chemistry 277 37991-38000. (doi:10.1074/jbc.M205087200)

Luan B, Goodarzi MO, Phillips NG, Guo X, Chen YD, Yao J, Allison M, Rotter JI, Shaw R \& Montminy M 2014 Leptin-mediated increases in catecholamine signaling reduce adipose tissue inflammation via activation of macrophage HDAC4. Cell Metabolism 19 1058-1065. (doi:10.1016/j.cmet.2014.03.024)

Lv S, Li J, Qiu X, Li W, Zhang C, Zhang ZN \& Luan B 2017 A negative feedback loop of ICER and NF-kappaB regulates TLR signaling in innate immune responses. Cell Death and Differentiation 24 492-499. (doi:10.1038/cdd.2016.148)

Maher JM, Dieter MZ, Aleksunes LM, Slitt AL, Guo G, Tanaka Y, Scheffer GL, Chan JY, Manautou JE, Chen Y, et al. 2007 Oxidative and electrophilic stress induces multidrug resistance-associated protein transporters via the nuclear factor-E2-related factor-2 transcriptional pathway. Hepatology 46 1597-1610. (doi:10.1002/hep.21831)

Marchesini G, Bugianesi E, Forlani G, Cerrelli F, Lenzi M, Manini R, Natale S, Vanni E, Villanova N, Melchionda N, et al. 2003 Nonalcoholic fatty liver, steatohepatitis, and the metabolic syndrome. Hepatology 37 917-923. (doi:10.1053/jhep.2003.50161)

Marchmont RJ \& Houslay MD 1980 Insulin trigger, cyclic AMPdependent activation and phosphorylation of a plasma membrane cyclic AMP phosphodiesterase. Nature 286 904-906. (doi:10.1038/286904a0)

Merrell MD, Jackson JP, Augustine LM, Fisher CD, Slitt AL, Maher JM, Huang W, Moore DD, Zhang Y, Klaassen CD, et al. 2008 The Nrf2 activator oltipraz also activates the constitutive androstane receptor. Drug Metabolism and Disposition 36 1716-1721. (doi:10.1124/ dmd.108.020867)

Mihaylova MM, Vasquez DS, Ravnskjaer K, Denechaud PD, Yu RT, Alvarez JG, Downes M, Evans RM, Montminy M \& Shaw RJ 2011 Class IIa histone deacetylases are hormone-activated regulators of FOXO and mammalian glucose homeostasis. Cell 145 607-621. (doi:10.1016/j. cell.2011.03.043)

Murosaki S, Lee TR, Muroyama K, Shin ES, Cho SY, Yamamoto Y \& Lee SJ 2007 A combination of caffeine, arginine, soy isoflavones, and L-carnitine enhances both lipolysis and fatty acid oxidation in 3T3-L1 and HepG2 cells in vitro and in KK mice in vivo. Journal of Nutrition $1372252-2257$.

Muroyama K, Murosaki S, Yamamoto Y, Odaka H, Chung HC \& Miyoshi M 2003 Anti-obesity effects of a mixture of thiamin, arginine, caffeine, and citric acid in non-insulin dependent diabetic KK mice. Journal of Nutritional Science and Vitaminology 49 56-63. (doi:10.3177/ jnsv.49.56)

Norris AW, Chen L, Fisher SJ, Szanto I, Ristow M, Jozsi AC, Hirshman MF, Rosen ED, Goodyear LJ, Gonzalez FJ, et al. 2003 Muscle-specific PPARgamma-deficient mice develop increased adiposity and insulin resistance but respond to thiazolidinediones. Journal of Clinical Investigation 112 608-618. (doi:10.1172/JCI17305)

Northrop G \& Parks RE Jr 1964 The effects of adrenergic blocking agents and theophylline on 3',5'-Amp-induced hyperglycemia. Journal of Pharmacology and Experimental Therapeutics 145 87-91.

Patarrao RS, Lautt WW \& Macedo MP 2015 Acute glucagon induces postprandial peripheral insulin resistance. PLOS ONE 10 e0127221. (doi:10.1371/journal.pone.0127221)

Peng Z, Borea PA, Varani K, Wilder T, Yee H, Chiriboga L, Blackburn MR, Azzena G, Resta G \& Cronstein BN 2009 Adenosine signaling contributes to ethanol-induced fatty liver in mice. Journal of Clinical Investigation 119 582-594. (doi:10.1172/JCI37409)
Pilkis SJ, Claus TH, Johnson RA \& Park CR 1975 Hormonal control of cyclic 3':5'-AMP levels and gluconeogenesis in isolated hepatocytes from fed rats. Journal of Biological Chemistry 250 6328-6336.

Ponce NE, Sanmarco LM, Eberhardt N, Garcia MC, Rivarola HW, Cano RC \& Aoki MP 2016 CD73 Inhibition shifts cardiac macrophage polarization toward a microbicidal phenotype and ameliorates the outcome of experimental chagas cardiomyopathy. Journal of Immunology 197 814-823. (doi:10.4049/jimmunol.1600371)

Rosenberg PA, Knowles R, Knowles KP \& Li Y 1994 Beta-adrenergic receptor-mediated regulation of extracellular adenosine in cerebral cortex in culture. Journal of Neuroscience 14 2953-2965.

Sammons MF \& Lee EC 2015 Recent progress in the development of small-molecule glucagon receptor antagonists. Bioorganic and Medicinal Chemistry Letters 25 4057-4064. (doi:10.1016/j. bmcl.2015.07.092)

Schmittgen TD \& Livak KJ 2008 Analyzing real-time PCR data by the comparative C(T) method. Nature Protocols 3 1101-1108. (doi:10.1038/nprot.2008.73)

Schuetz EG, Strom S, Yasuda K, Lecureur V, Assem M, Brimer C, Lamba J, Kim RB, Ramachandran V, Komoroski BJ, et al. 2001 Disrupted bile acid homeostasis reveals an unexpected interaction among nuclear hormone receptors, transporters, and cytochrome P450. Journal of Biological Chemistry 276 39411-39418. (doi:10.1074/ jbc.M106340200)

Strouch MB, Jackson EK, Mi Z, Metes NA \& Carey GB 2005 Extracellular cyclic AMP-adenosine pathway in isolated adipocytes and adipose tissue. Obesity Research 13 974-981. (doi:10.1038/ oby.2005.114)

Sun B \& Karin M 2012 Obesity, inflammation, and liver cancer. Journal of Hepatology 56 704-713. (doi:10.1016/j.jhep.2011.09.020)

Tachibana K, Kobayashi Y, Tanaka T, Tagami M, Sugiyama A, Katayama T, Ueda C, Yamasaki D, Ishimoto K, Sumitomo M, et al. 2005 Gene expression profiling of potential peroxisome proliferator-activated receptor (PPAR) target genes in human hepatoblastoma cell lines inducibly expressing different PPAR isoforms. Nuclear Receptor 33. (doi:10.1186/1478-1336-3-3)

Unger RH \& Cherrington AD 2012 Glucagonocentric restructuring of diabetes: a pathophysiologic and therapeutic makeover. Journal of Clinical Investigation 122 4-12. (doi:10.1172/JCI60016)

Van Dongen MG, Geerts BF, Morgan ES, Brandt TA, de Kam ML, Romijn JA, Cohen AF, Bhanot S \& Burggraaf J 2014 First proof of pharmacology in humans of a novel glucagon receptor antisense drug. Journal of Clinical Pharmacology 55 298-306. (doi:10.1002/ jcph.396)

von Meyenn F, Porstmann T, Gasser E, Selevsek N, Schmidt A, Aebersold R \& Stoffel M 2013 Glucagon-induced acetylation of Foxa2 regulates hepatic lipid metabolism. Cell Metabolism 17 436-447. (doi:10.1016/j. cmet.2013.01.014)

Wang B, Moya N, Niessen S, Hoover H, Mihaylova MM, Shaw RJ, Yates JR 3rd, Fischer WH, Thomas JB \& Montminy M 2011 A hormonedependent module regulating energy balance. Cell 145 596-606. (doi:10.1016/j.cell.2011.04.013)

Zhang ZN, Gong L, Lv S, Li J, Tai X, Cao W, Peng B, Qu S, Li W, Zhang C, et al. 2016 SIK2 regulates fasting-induced PPARalpha activity and ketogenesis through p300. Scientific Reports 6 23317. (doi:10.1038/ srep23317)

Zumstein P, Zapf J \& Froesch ER 1974 Effects of hormones on cyclic AMP release from rat adipose tissue in vitro. FEBS Letters 49 65-69. (doi:10.1016/0014-5793(74)80633-2)

Received in final form 16 May 2017

Accepted 17 May 2017

Accepted Preprint published online 17 May 2017 http://joe.endocrinology-journals.org

DOI: $10.1530 / J O E-16-0649$
๑ 2017 Society for Endocrinology Printed in Great Britain
Published by Bioscientifica Ltd. 